\title{
Inhibition of apolipoprotein B100 secretion by lipid-induced hepatic endoplasmic reticulum stress in rodents
}

\author{
Tsuguhito Ota, Constance Gayet, and Henry N. Ginsberg \\ Department of Medicine, Columbia University College of Physicians and Surgeons, New York, New York, USA.
}

\begin{abstract}
ER stress can cause hepatic insulin resistance and steatosis. Increased VLDL secretion could protect the liver from ER stress-induced steatosis, but the effect of lipid-induced ER stress on the secretion of VLDL is unknown. To determine the effect of lipids on hepatic ER stress and VLDL secretion, we treated McA-RH7777 liver cells with free fatty acids. Prolonged exposure increased cell triglycerides, induced steatosis, and increased ER stress. Effects on apoB100 secretion, which is required for VLDL assembly, were parabolic, with moderate free fatty acid exposure increasing apoB100 secretion, while greater lipid loading inhibited apoB100 secretion. This decreased secretion at higher lipid levels was due to increased protein degradation through both proteasomal and nonproteasomal pathways and was dependent on the induction of ER stress. These findings were supported in vivo, where intravenous infusion of oleic acid (OA) in mice increased ER stress in a durationdependent manner. apoB secretion was again parabolic, stimulated by moderate, but not prolonged, OA infusion. Inhibition of ER stress was able to restore OA-stimulated apoB secretion after prolonged OA infusion. These results suggest that excessive ER stress in response to increased hepatic lipids may decrease the ability of the liver to secrete triglycerides by limiting apoB secretion, potentially worsening steatosis.
\end{abstract}

\section{Introduction}

ER stress is caused by the accumulation of unfolded and misfolded proteins in the ER lumen and is associated with several human diseases $(1,2)$. To maintain ER function when the secretory pathway is compromised, cells initiate an adaptive response called the unfolded protein response (UPR), in which the transcription of genes encoding ER chaperones and folding catalysts is upregulated to increase protein-folding activity (3). Additionally, ER stress is associated with reductions in the translation of secretory proteins $(4,5)$. Although the relationship between ER stress and some disease-related proteins has been studied using animal models, the role of ER stress in metabolic disease remains less well defined (6).

Hepatic steatosis and increased secretion of apoB-containing lipoproteins (Lps), particularly VLDL, are characteristic concomitants of insulin resistance (IR), the metabolic syndrome, and type 2 diabetes mellitus (7-10) and are increasing clinical problems (11, 12). Recent evidence suggests that increased hepatic triglycerides (TGs) are associated with both hepatic IR and ER stress. Thus, Ozcan et al. (13) showed that ER stress, as indicated by increases in the $78-\mathrm{kDa}$ glucose-regulated/binding immunoglobulin protein (GRP78) and phosphorylation of the ER membrane protein PKRlike ER kinase (PERK) and its target, eukaryotic initiation factor $2 \alpha(\mathrm{eIF} 2 \alpha)$, was present in livers of high-fat diet-fed C57BL/6J or $o b / o b$ mice. There was also activation of JNK, a finding that the

Nonstandard abbreviations used: eIF2 $\alpha$, eukaryotic initiation factor $2 \alpha$; FA, fatty acid; GRP78, 78-kDa glucose-regulated/binding immunoglobulin protein; IL, Intralipid plus lipoprotein lipase; IR, insulin resistance; IRE-1 $\alpha$, inositol requiring ER-tonucleus signaling protein-1 $\alpha$; Lp, lipoprotein; McA, McA-RH7777; MTP, microsomal TG transfer protein; OA, oleic acid; PBA, 4-phenyl butyric acid; PERK, ER membrane protein PKR-like ER kinase; TG, triglyceride; UPR, unfolded protein response; XBP1, $\mathrm{x}$-box-binding protein-1.

Conflict of interest: The authors have declared that no conflict of interest exists. Citation for this article: J. Clin. Invest. 118:316-332 (2008). doi:10.1172/JCI32752. authors linked to the development of hepatic IR (13). GRP78, an ER chaperone and stress sensor, is also increased in livers of $\mathrm{C} 57 \mathrm{BL} / 6 \mathrm{~J}-d b / d b$ mice (14). Other studies suggest a role for obesity and/or excess energy, in the form of fatty acids (FAs) or TGs, as signals for ER stress, possibly through inflammatory mediators such as JNK (15-17).

If hepatic ER stress is induced by accumulation of FAs or TGs (or associated metabolites), it might inhibit the translation and/or intracellular transport and secretion of a complex protein such as apo $B$, predisposing to greater steatosis. apoB is particularly prone to co- and posttranslational regulation (18-20). However, it is not clear whether increased delivery of FAs to the liver and/or accumulation of liver TGs, situations commonly seen in the IR state, will produce ER stress or, more importantly, whether ER stress induced in this way affects the secretion of apoB. Studies of TG and apoB secretion in other models of hepatic ER stress have yielded varied results. Hyperhomocysteinemia, which is associated with hepatic steatosis in humans $(21,22)$, causes both ER stress and increased TG secretion in mice (23). On the other hand, tunicamycin and DTT $(24,25)$, both inducers of ER stress and the UPR, can reduce the secretion of apoB-Lps. Glucosamine-induced ER stress is also associated with decreased apoB secretion from the liver (26).

By contrast, a significant body of work from our group and other laboratories (18) has demonstrated increased secretion of apoB-Lps in response to increased hepatic FAs and/or TGs. In an attempt to integrate all the available data, we hypothesized that modest increases in the delivery of FAs to the liver and/or modest accumulation of hepatic lipids would increase apoB secretion despite some stimulation of ER stress, while more significant accumulation of hepatic lipids would further increase ER stress, leading to reduced apoB secretion. To test this hypothesis, we investigated the in vitro effects of incubating McA-RH7777 (McA) cultured rat hepatoma cells with oleic acid (OA) or a mixture of 
A

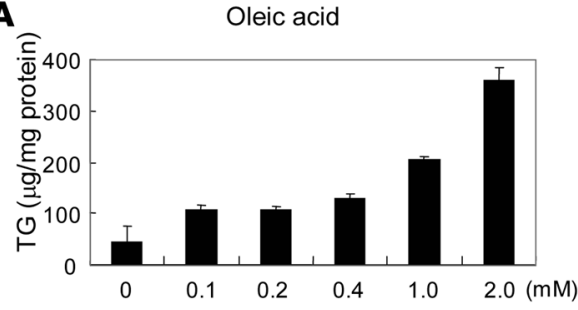

B

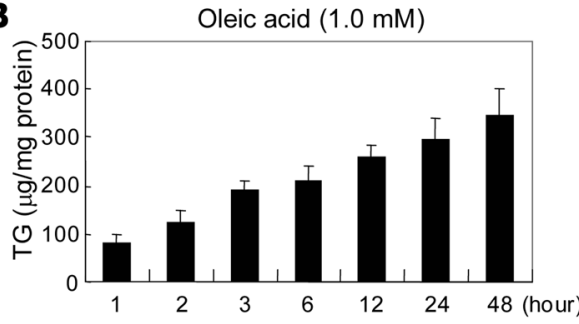

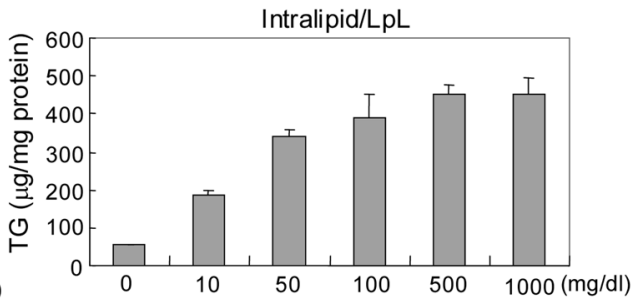

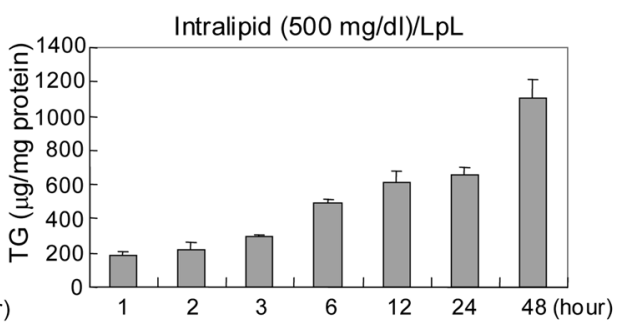

\section{Figure 1}

Incubation of McA cells with OA or IL results in dose- and duration-dependent increases in cell TG content. (A) Incubation of McA cells with OA (0.1-2.0 $\mathrm{mM}$; black bars) or IL (10-1,000 mg/dl; gray bars) for 6 hours resulted in dosedependent increases in cellular TGs. (B) Incubation of McA cells with 1.0 $\mathrm{mM}$ OA or $500 \mathrm{mg} / \mathrm{dl} \mathrm{IL}$ for 1-48 hours increased cellular TG content in a duration-dependent manner. The incubation medium was changed every 12 hours. TG levels are presented as microgram per milligram cell protein. Data are mean \pm SD ( $n=3$ for each condition). $\mathrm{LpL}$, lipoprotein lipase. the TG emulsion Intralipid and lipoprotein lipase (IL) and the in vivo effects of intravenous infusions of OA or Intralipid into male C57BL/6J mice on hepatic ER stress and apoB-Lp secretion.

\section{Results}

Incubation of McA cells with OA or IL results in dose- and duration-dependent increases in cell TG content. To develop an in vitro model of steatosis, we incubated $\mathrm{OA}$ or IL at concentrations ranging from 0.1 to $2.0 \mathrm{mM}$ for OA or 10 to $1,000 \mathrm{mg} / \mathrm{dl}$ for IL for 6 hours in McA cells. Incubation with $\mathrm{OA}$ resulted in an increase in cell TGs from control levels of $45.0 \pm 13.0 \mu \mathrm{g} / \mathrm{mg}$ cell protein in the absence of OA to $358.7 \pm 24.3 \mu \mathrm{g} / \mathrm{mg}$ cell protein in the presence of $2.0 \mathrm{mM} \mathrm{OA}$; incubation with IL resulted in an increase in cell TGs from control levels of $54.3 \pm 1.7 \mu \mathrm{g} / \mathrm{mg}$ cell protein in the absence of IL to $453.2 \pm 43.2$ $\mu \mathrm{g} / \mathrm{mg}$ cell protein in the presence of $1,000 \mathrm{mg} / \mathrm{dl}$ IL (Figure 1A). Effects of duration of incubations were determined using $1.0 \mathrm{mM}$ $\mathrm{OA}$ and $500 \mathrm{mg} / \mathrm{dl} \mathrm{IL}$, with fresh medium provided every 12 hours (Figure 1B). At these concentrations, OA and IL increased total cellular TG levels in McA cells in a duration-dependent manner.

Incubation of McA cells with OA or IL increases GRP78 expression in $M c A$ cells. We next sought to demonstrate a link between lipid loading and ER stress. Incubations of McA cells with increasing concentrations of either OA or IL for increasing durations also led to dose- and duration-dependent increases in mRNA levels of GRP78, an ER chaperone that is a central indicator of ER stress (27) (Figure 2A). There were no effects of 3-hour incubations at any dose of OA or IL. However, after 6-hour incubations, significant increases in GRP78 mRNA began to be observed with higher doses of each source of FAs, and marked elevations of GRP78 mRNA were seen at most concentrations of OA and IL after 16 hours of incubation. In this experiment, the 6-hour incubations with $0.4 \mathrm{mM} \mathrm{OA}$ were associated with cell TG levels of $128.5 \pm 10.3(0.4 \mathrm{mM}) \mu \mathrm{g} / \mathrm{mg}$ cell protein, whereas the 16 -hour incubations with $0.4 \mathrm{mM}$ OA resulted in TG levels of $166.5 \pm 17.6 \mu \mathrm{g} / \mathrm{mg}$ cell protein. Incubations of cells with $500 \mathrm{mg} / \mathrm{dl}$ IL for 6 hours resulted in TG levels of $448.9 \pm 30.3 \mu \mathrm{g} / \mathrm{mg}$ cell protein, whereas 16 -hour incubations with $500 \mathrm{mg} / \mathrm{dl}$ IL produced TG levels of $628.5 \pm 64.4 \mu \mathrm{g} / \mathrm{mg}$ cell protein. These conditions were used to look at several other markers of ER stress.

To determine whether the increases in GRP78 mRNA were associated with elevations in the protein levels, we incubated McA cells with $0.4 \mathrm{mM}$ OA or $500 \mathrm{mg} / \mathrm{dl}$ IL for 3, 6, or 16 hours. GRP78 protein expression was not significantly changed by incubation with either OA or IL after 3 or 6 hours of incubation (Figure 2B). However, both lipids increased levels of GRP78 protein after a 16-hour treatment (2.9- and 2.7-fold, respectively; $P<0.001$ for both vs. control incubations) (Figure 2C). These changes correlated with the dose- and time-dependent responses of TG loading of the cells (see above and Figure 1).

Incubation of McA cells with OA or IL induces phosphorylation of eIF $2 \alpha$ in McA cells. To determine whether lipid-loading induces hepatic ER stress downstream of GRP78, we examined its effects on components of the UPR. One component of the UPR involves phosphorylation of cytosolic eIF $2 \alpha$ on Ser 51 by the ER-localized kinase PERK (4). Phosphorylated eIF $2 \alpha$ mediates both a transient decrease in global translation and the translational upregulation of stress-induced mRNAs (5). We determined the phosphorylation status of eIF $2 \alpha$ (Ser51) using phospho-specific antibodies during lipid loading of McA cells. Incubation of McA cells for 3 or 6 hours with OA $(0.4 \mathrm{mM})$ or IL $(500 \mathrm{mg} / \mathrm{dl})$ had no significant effect on the levels of total or phosphorylated eIF2 $\alpha$ (Figure 3A). However, incubation at these concentrations for 16 hours induced significant phosphorylation of eIF2 $\alpha$ (7.5- and 6.7-fold, respectively; $P<0.01$ vs. control incubations) without changing the total eIF $2 \alpha$ protein levels (Figure 3B).

Incubation of McA cells with OA or IL induces XBP1 mRNA alternative splicing and the nuclear translocation of the alternative form of the protein. Another branch of the UPR is mediated by activation of $\mathrm{x}$-box-binding protein-1 (XBP1) by inositol requiring ER-tonucleus signaling protein-1 $\alpha$ (IRE- $1 \alpha)$, which is an ER-localized protein. IRE- $1 \alpha$ activates XBP1 by splicing its mRNA in response to ER stress $(28,29)$. The splicing results in the excision of a 26-bp fragment and a frameshift that can be identified by the loss of a Pst 1 restriction site and a longer PCR product (28). McA cells were exposed for 3,6 , or 16 hours to OA $(0.4 \mathrm{mM})$ or IL $(500 \mathrm{mg} / \mathrm{dl})$, and the extent of $X B P 1$ splicing was characterized by determining the relative amounts of 300-bp (Pst $1+$ derived from native, unspliced mRNA) and 601-bp (Pst1- derived from activated, spliced mRNA) PCR products after Pst 1 digestion. Incubation of cells with $5 \mu \mathrm{g} /$ $\mathrm{ml}$ tunicamycin, which was used as a positive control for ER stress, resulted in complete processing of XBP1 mRNA, and only larger 601-bp products were seen after Pst 1 digestion (Figure 4, A and B, 


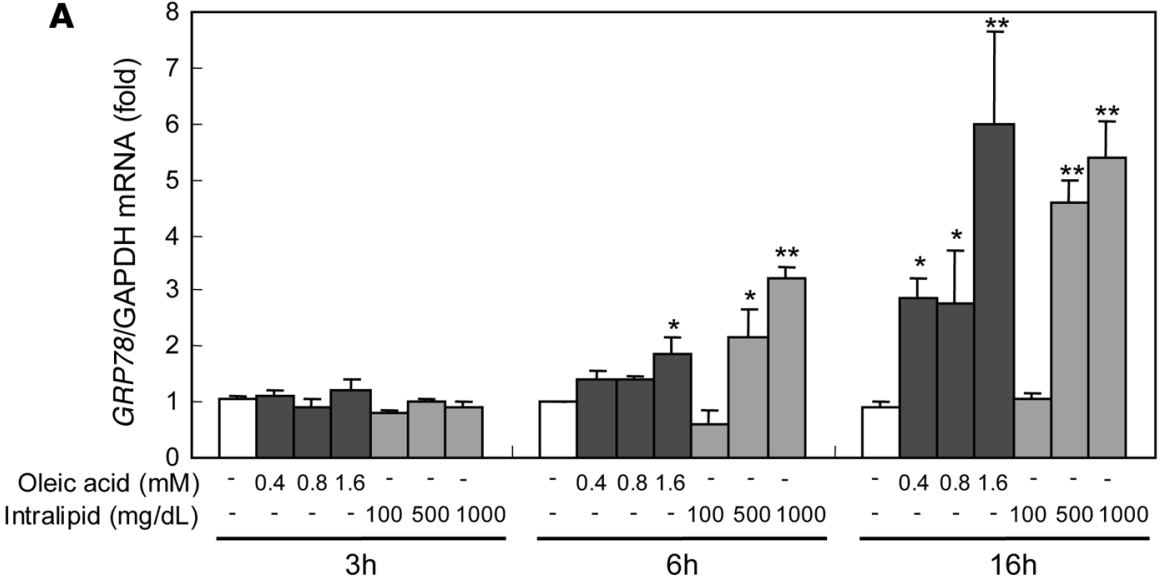

B

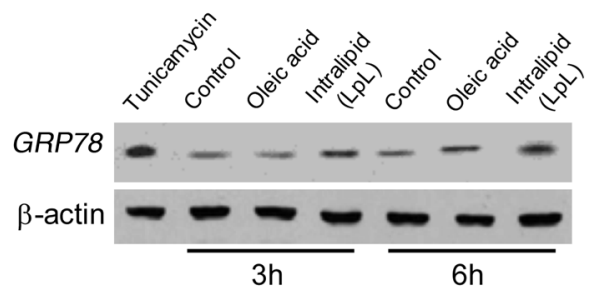

C

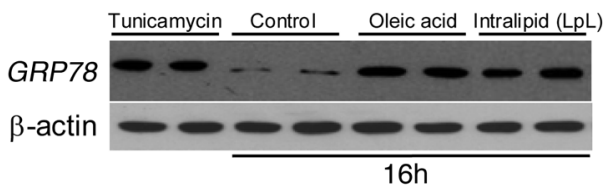

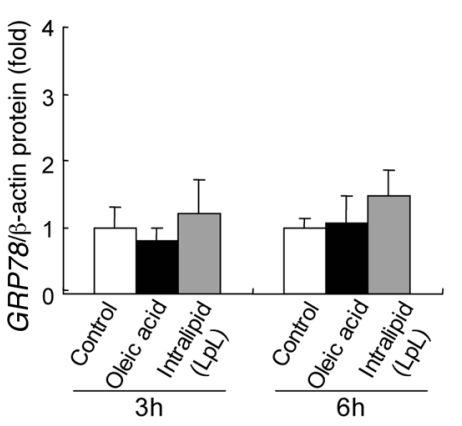

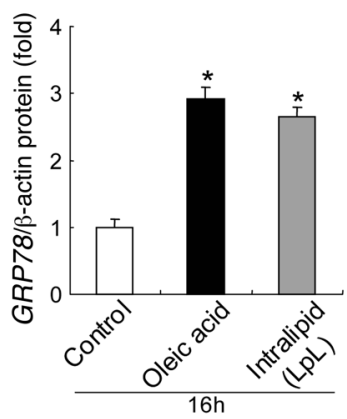

Figure 2

Incubation of McA cells with OA or IL increases GRP78 mRNA and protein levels. (A). Incubation of McA cells with either $\mathrm{OA}$ $(0.4-1.6 \mathrm{mM})$ or IL (100-1,000 mg/dl) for 3 hours did not affect mRNA levels of GRP78. However, incubation for 6 or 16 hours with OA or IL increased GRP78 mRNA in a dosedependent manner. Data are mean $\pm S D$ normalized to cells incubated without $O A$ or IL ( $n=6$ for each condition); ${ }^{\star} P<0.05$, ${ }^{* *} P<0.001$ versus control incubations. (B) Incubation of McA cells for 3 or 6 hours with OA $(0.4 \mathrm{mM})$ or IL $(500 \mathrm{mg} / \mathrm{dl})$ did not significantly affect GRP78 protein levels. (C) GRP78 protein was significantly increased by incubation with either $\mathrm{OA}(0.4 \mathrm{mM})$ or IL $(500 \mathrm{mg} / \mathrm{dl})$ for 16 hours. ER stress, as indicated by increased GRP78, was also induced by a 3-hour treatment with tunicamycin $(5 \mu \mathrm{g} / \mathrm{ml})$ as a positive control. Protein data are mean \pm SD normalized to cells incubated without OA or IL ( $n=3$ for each condition); ${ }^{*} P<0.001$ versus control incubations. far right lane). In the control condition, the majority of the $X B P 1$ PCR product was $300 \mathrm{bp}$ (Pst1+), indicating predominance of the native, unspliced XBP1 mRNA (Figure 4, A, lanes 1 and 4, and B, lanes 1-3 from left). There was no effect, compared with control, of 3-hour (Figure 4A, lanes 2 and 3) or 6-hour incubations (Figure $4 \mathrm{~A}$, lanes 5 and 6) with either OA or IL on XBP1 mRNA splicing. However, in cells exposed to OA or IL for 16 hours, a larger proportion of the XBP1 PCR product was the 601-bp length (OA $43 \% \pm 6 \%$; IL $38 \% \pm 4 \%$ ) (Pst1-), indicating greater XBP1 mRNA splicing in the presence of ER stress (Figure 4B, lanes 4-9).

The spliced XBP1 mRNA produces a protein that is a potent basic leucine zipper transcription factor after translocation into the nucleus (29). Although the nuclear content of XBP1 was not increased after 3 or 6 hours of incubation of McA cells with either OA or IL (Figure 4C), nuclear translocation of XBP1 protein was clearly increased after 16 hours of incubation of either OA (Figure 4D, lanes 5 and 6 ) or IL (Figure 4D, lanes 7 and 8) compared with control cells incubated without either lipid (Figure 4D, lanes 3 and 4$)(P<0.05$ and $P<0.01$ vs. control incubations, respectively). Thus, prolonged lipid loading by either OA or IL activated XBP1 in McA cells, as evidenced by splicing of mRNA and nuclear translocation of XBP1.

There is a parabolic relationship between lipid loading-mediated ER stress and apoB100 secretion in McA cells. The above results demonstrated that we could induce hepatic ER stress by loading the cells with FAs and/or TGs. Because delivery of FAs or TGs to cultured liver cells is typically associated with increased apoB secretion (18), we wanted to characterize the relationship between FA/TG-induced hepatic ER stress and the assembly and secretion of apoB-Lps. Cells were treated with varying doses of OA for 3, 6, or 16 hours and then labeled with $\left[{ }^{35} \mathrm{~S}\right]$ methionine. Media were collected, and apoB100, apoB48, apoA-I, and albumin were immunoprecipitated with specific antibodies. Incubation of McA cells with $0.4,0.8$, or $1.2 \mathrm{mM}$ OA for 3 hours induced progressive, dose-related increases in apoB100 secretion compared with incubations in the absence of $\mathrm{OA}(P<0.01)$ (Figure 5A). Both $0.4 \mathrm{mM}$ and $0.8 \mathrm{mM}$ OA continued to stimulate apoB100 secretion after 6 hours of incubation, but the effect of lipid loading on apoB100 secretion was lost after 6-hour incubations at $1.2 \mathrm{mM}$ OA. Furthermore, while $0.4 \mathrm{mM} \mathrm{OA}$ still stimulated apoB100 secretion after 16 hours, $0.8 \mathrm{mM}$ no lon- 

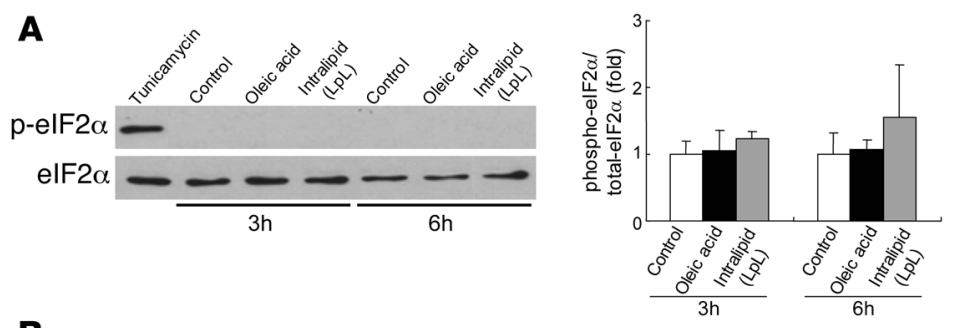

B

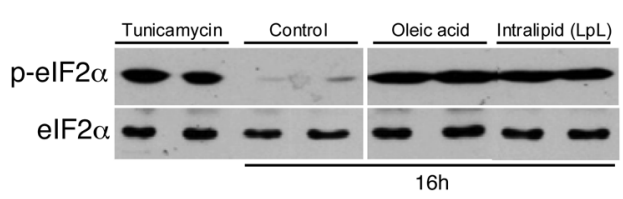

Figure 3

$\mathrm{OA}$ or IL induces phosphorylation of elF $2 \alpha$ in McA cells. (A) Incubation of McA cells for 3 or 6 hours with OA $(0.4 \mathrm{mM})$ or IL $(500 \mathrm{mg} / \mathrm{dl})$ did not significantly induce phosphorylation of elF2 $\alpha$. (B) Phosphorylation of elF2 $\alpha$ was significantly increased by incubation with either OA $(0.4 \mathrm{mM})$ or IL $(500 \mathrm{mg} / \mathrm{dl})$ for 16 hours without a change in total elF2 $\alpha$ protein level. ER stress was also induced by a 3-hour treatment with tunicamycin $(5 \mu \mathrm{g} / \mathrm{ml})$ as a positive control. Lanes were run on the same gel but were noncontiguous. Data are mean \pm SD normalized to cells incubated without OA or IL ( $n=3$ for each condition); ${ }^{*} P<0.01$ versus control incubations.

ger had an effect, and $1.2 \mathrm{mM}$ OA for 16 hours actually inhibited apoB100 secretion compared with control cells. These complex dose-related relationships between OA-induced lipid loading and apoB100 secretion at 16 hours were not observed with apoB48, apoA-I, or albumin (Figure 5B). However, when we incubated McA cells for 16 hours with $1.6 \mathrm{mM} \mathrm{OA}$, which was associated with the highest levels of GRP78 gene expression (Figure 2A), there were significant reductions in the secretion of all 4 proteins (Figure 5C). When IL was used as a means of delivering FAs to the cells, there was a dose-dependent increase in ER stress, indicated by rising levels of GRP78 protein (Figure 5D). Concomitantly, we observed a parabolic response pattern for apoB100 (Figure 5E): compared with incubation of McA cells without any IL, incubation with 100 $\mathrm{mg} / \mathrm{dl}$ of IL for 16 hours increased apoB100 secretion; incubation with $500 \mathrm{mg} / \mathrm{dl}$ IL resulted in apoB100 secretion at the same level as control; and incubation with $1,000 \mathrm{mg} / \mathrm{dl} \mathrm{IL}$ (which caused the greatest rise in GRP78; Figure 5D) caused a reduction in apoB100 secretion. IL had no effect on apoB48, apoA-I, or albumin secretion at any of the concentrations used.

$\mathrm{OA}$, at $0.4,0.8$, and $1.2 \mathrm{mM}$, had no effect on total protein synthesis in the McA cells, as determined by total TCA-precipitable radioactivity; the $30 \%$ reduction in TCA-precipitable radioactivity seen with $1.6 \mathrm{mM}$ OA indicated an effect of this dose of OA on global protein synthesis and secretion, consistent with the reduction in secretion of all 4 proteins tested (Figure 5F). IL, at the doses tested, had no effect on TCA-precipitable radioactivity. Normal trypan blue staining confirmed a lack of toxicity of OA and IL at any concentration and duration of treatment (data not shown). These results indicate a complex, parabolic relationship between the degree of lipid-induced ER stress and apoB100 secretion.

ER stress-induced inhibition of apoB100 secretion is not associated with altered gene expression of either Apob or microsomal TG transfer protein. Since ER stress and the UPR significantly alter gene expression, we next determined the effects of ER stress on the expression of 2 key genes: Apob and microsomal TG transfer protein $(M t t p)$. There was no effect of incubating McA cells with increasing doses of either OA (0.4-1.6 mM) or IL (100-1,000 mg/dl), for varying periods, on the levels of Apob or Mttp mRNA (Figure 6).

$E R$ stress induces cotranslational proteasomal degradation of $a p o B$. With no evidence for effects of ER stress on apoB gene expression, we turned our attention to posttranscriptional pathways that regulate apoB secretion (18). When puromycin was used to synchronize translation of McA cells, the accumulation of newly synthesized, full-length apoB100 was dramatically reduced in cells preincubated with $1.2 \mathrm{mM}$ OA for 16 hours (Figure 7 top right, third lane for each time point) compared with cells incubated with either no OA or with $0.4 \mathrm{mM}$ OA for 16 hours. In contrast, pretreatment of the cells for 16 hours with $0.4 \mathrm{mM}$ OA moderately increased the appearance of full-length apoB100 (second lane for each time point) compared with cells incubated without OA. Importantly, cotreatment of the cells with lactacystin, a specific inhibitor of proteasomal degradation (30), substantially, although not completely, corrected the abnormality in the appearance of apoB100 seen with $1.2 \mathrm{mM} \mathrm{OA}$. (Figure 7, bottom right). There appears to have been a similar, but much less striking, abnormality in the appearance of apoB48 that was also reversed by lactacystin treatment. There was no effect of $O A$ on the rate of accumulation of new synthesized albumin (data not shown).

ER stress also induces nonproteasomal degradation of apoB100. In addition to cotranslational proteasomal degradation, there are a number of posttranslational pathways for degradation of apoB (18, 31). To further characterize the effects of FA-induced ER stress on intracellular degradation of apoB, pulse-chase studies were performed after preincubation of McA cells in the presence or absence of OA for 16 hours (Figure 8). The quantity of radiolabeled protein in the cell lysates at the 15-minute chase time point was taken as $100 \%$ of newly synthesized apoB 100 , apoB 48 , or albumin. Relative to incubation in the absence of OA, preincubation with $0.4 \mathrm{mM}$ OA caused increased apoB100 secretion (Figure 8A, bottom left) in association with decreased intracellular disappearance (Figure $8 \mathrm{~A}$, middle) and greater total recovery (Figure 8A, right) of newly synthesized $\left[{ }^{35} \mathrm{~S}\right]$ methionine-labeled apoB100 over a 90-minute pulse-chase protocol. This OA-mediated increase in apoB100 secretion and the rescue of apoB100 from intracellular degradation were lost after incubation with $0.8 \mathrm{mM}$ OA. Furthermore, preincubation with $1.2 \mathrm{mM}$ OA for 16 hours resulted in decreased apoB100 secretion associated with increased disappearance of intracellular apoB100. In contrast, there was no significant effect of preincubation of McA cells with as much as $1.2 \mathrm{mM}$ OA on either the secretion or intracellular degradation of apoB48 (Figure 8B) or albumin (Figure 8C). In view of the results with lactacystin in puromycinsynchronized cells, we next preincubated McA cells with varying amounts of OA for 16 hours and then radiolabeled the cells for 2 hours, with all incubations performed in the absence and presence of the specific proteasome inhibitor lactacystin. Surprisingly, inhibition of proteasomal degradation in this prolonged labeling study had no effect on ER stress-mediated inhibition of apoB100 secretion (Figure 8D). Overall, the results presented in Figures 7 and 8 indicate that the parabolic relationship between FA-induced ER 
A
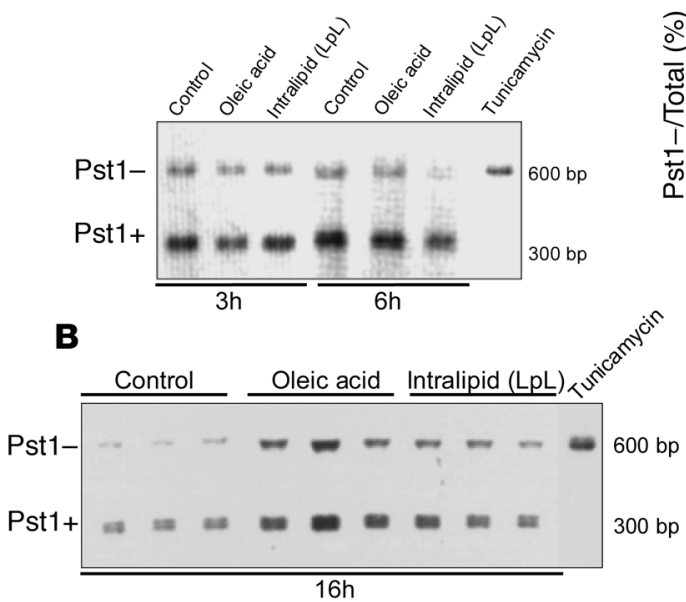

C

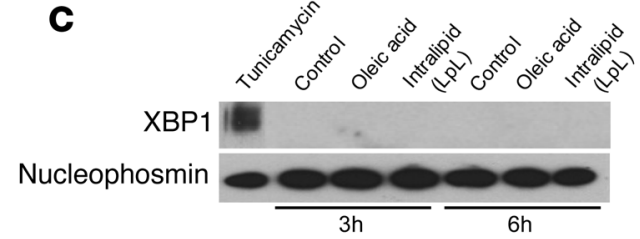

\section{D}

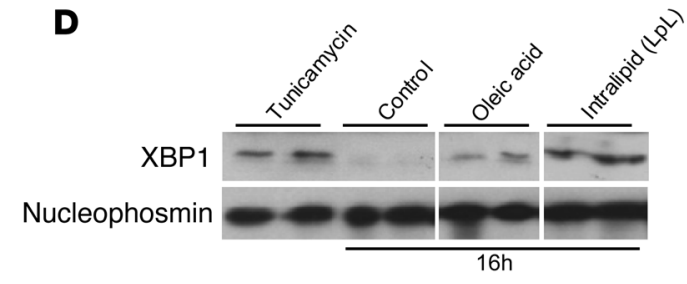

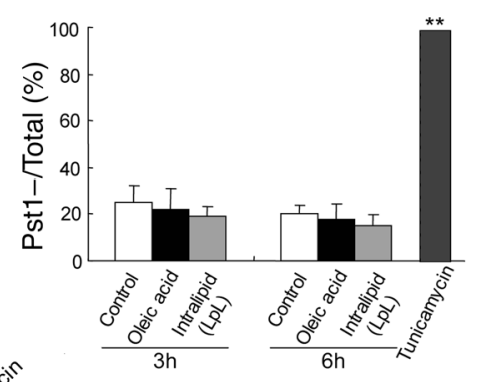
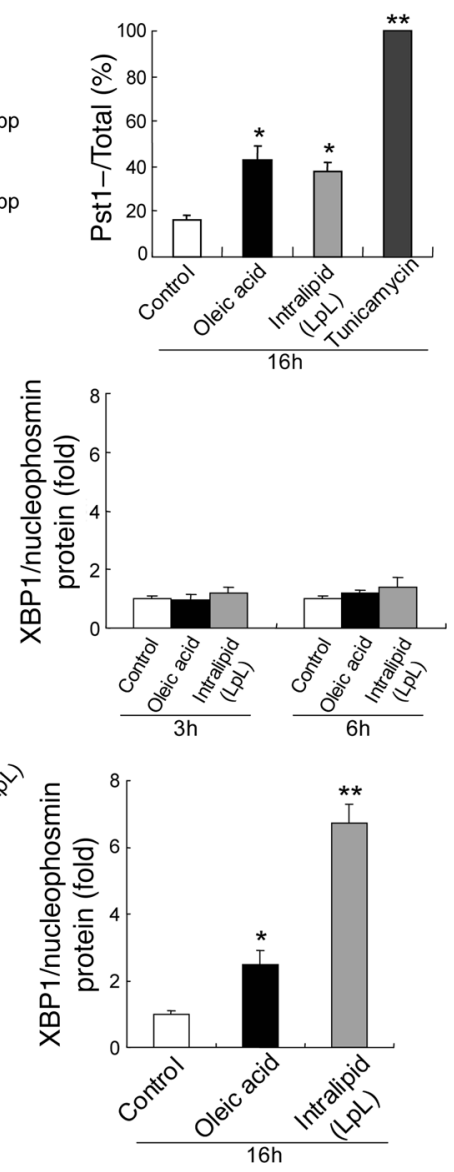

Figure 4

$O A$ or IL induces alternative splicing of XBP1 mRNA and translocation of the alternative form of the protein into the nucleus in McA cells. McA cells were exposed for 3 or 6 hours $(\mathbf{A})$ or for 16 hours $(B)$ to $O A(0.4 \mathrm{mM})$ or IL $(500 \mathrm{mg} / \mathrm{dl})$. XBP1 cDNA was amplified by PCR followed by incubation with Pst1. The products of the incubation with Pst1 are shown on the left; the bar graphs show the percentage of total XBP1 mRNA that was resistant to Pst1 and was, therefore, already spliced and activated. After 3 or 6 hours of incubation with OA or IL, most of the XBP1 PCR products were cut by Pst1 (Pst1+), producing a 300-bp amplification product, indicating a predominance of the native, unspliced form of XBP1 mRNA; less than $20 \%$ of total XBP1 was detected as the Pst1-, 601-bp amplification product, indicative of spliced XBP1 mRNA. By contrast, after a 16-hour incubation with either OA or IL, a larger proportion of the XBP1 PCR product was Pst1-and kept its full 601-bp length (OA $43 \% \pm 6 \%$; IL $38 \% \pm 4 \%$ ), indicating partial XBP1 mRNA splicing and presence of ER stress. Complete XBP1 activation and splicing were induced by a 3-hour treatment with tunicamycin $(5 \mu \mathrm{g} / \mathrm{ml})$ as a positive control. Data are mean $\pm \mathrm{SD}\left(n=6\right.$ for each condition); ${ }^{*} P<0.05$, ${ }^{\star \star} P<0.01$ versus control incubations (without $\mathrm{OA}$ or IL). The nuclear content of XBP1 was not increased after a 6-hour incubation with OA or IL (C) but was increased after incubation with either lipid source for 16 hours (D). Nucleophosmin is shown as a control for the efficiency of the nuclear extraction. ER stress was also induced by a 3-hour treatment with $5 \mu \mathrm{g} / \mathrm{ml}$ tunicamycin as a positive control. Lanes were run on the same gel but were noncontiguous. Data are mean \pm SD normalized to cells incubated without $\mathrm{OA}$ or IL ( $n=3$ for each condition); ${ }^{*} P<0.05,{ }^{* \star} P<0.01$ versus control incubations. stress and apoB100 secretion is associated with both proteasomal and nonproteasomal degradation of apoB100. The latter pathway appears, based on these experiments, to be the dominant one.

As noted above, there are several posttranslational pathways for apoB degradation in hepatocytes, including a recently described pathway that is stimulated by increased availability of polyunsaturated FAs. This latter degradation is inhibited by vitamin E or desferrioxamine (32). We cotreated McA cells with either vitamin $\mathrm{E}$ or desferrioxamine during incubations with varying concentrations of OA for 16 hours. Neither treatment affected the parabolic relationship between $O A$ and $a p o B$ secretion, suggesting that lipid peroxidation and/or reactive oxygen species were not playing roles in the ER stress-induced degradation of apoB100 (Supplemental Figure 1; supplemental material available online with this article; doi:10.1172/JCI32752DS1).

4-Phenyl butyric acid inhibits lipid-induced ER stress and reverses the inbibition of apoB100 secretion by bigh concentrations of $O A$. Based on the data to this point, we wished to determine apoB100 secretion when lipid loading was dissociated from ER stress. 4-Phenyl butyric acid (PBA) is a low-molecular-weight chaperone known to stabilize protein conformation and improve ER folding capacity $(33,34)$. Treatment of McA cells with PBA suppressed OA-induced increases of GRP78 expression as well as the phosphorylation of eIF2 $\alpha$ (Figure 9A). Importantly, PBA reduced lipid-induced ER stress without affecting the rise in cellular TG content after incubations with OA (Figure 9B). PBA treatment reversed the parabolic effects of OA on apoB100 secretion. Thus, secretion of apoB100 doubled after incubations of McA cells with $0.4 \mathrm{mM}$ OA for 16 hours compared with cells incubated without $\mathrm{OA}$; similar increases were seen after incubations with $0.8 \mathrm{mM}$ and $1.2 \mathrm{mM}$ OA for 16 hours (Figure 9C). These results indicated that PBA prevented the inhibition of apoB100 secretion previously observed in association with OA-induced ER stress, without changing TG content in vitro. Furthermore, under these experimental conditions, the effects of PBA were selective for apoB100: there were no significant effects of PBA on apoB48, apoA-I, or albumin secretion (data not shown). Of note, pretreatment of 
A
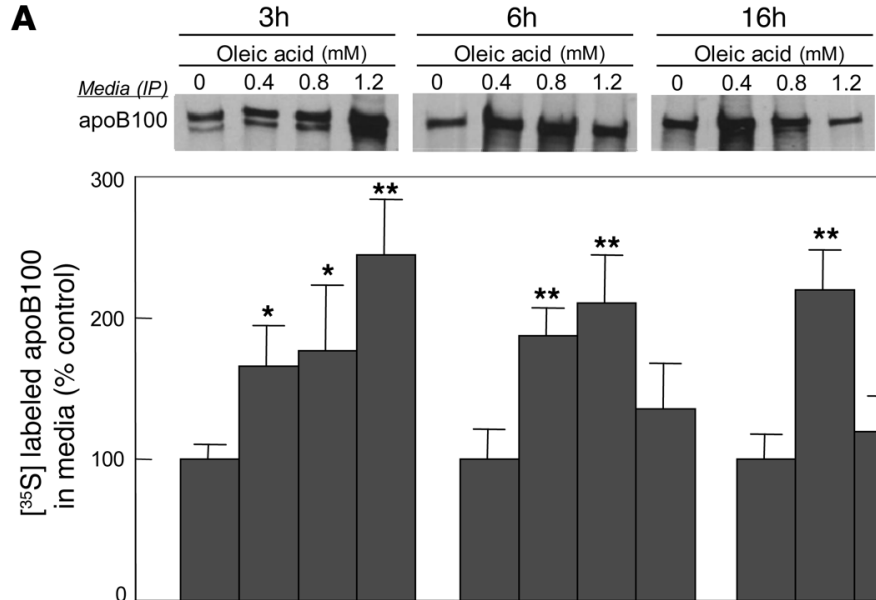

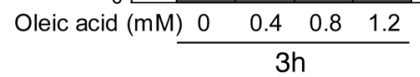

2

\section{B}
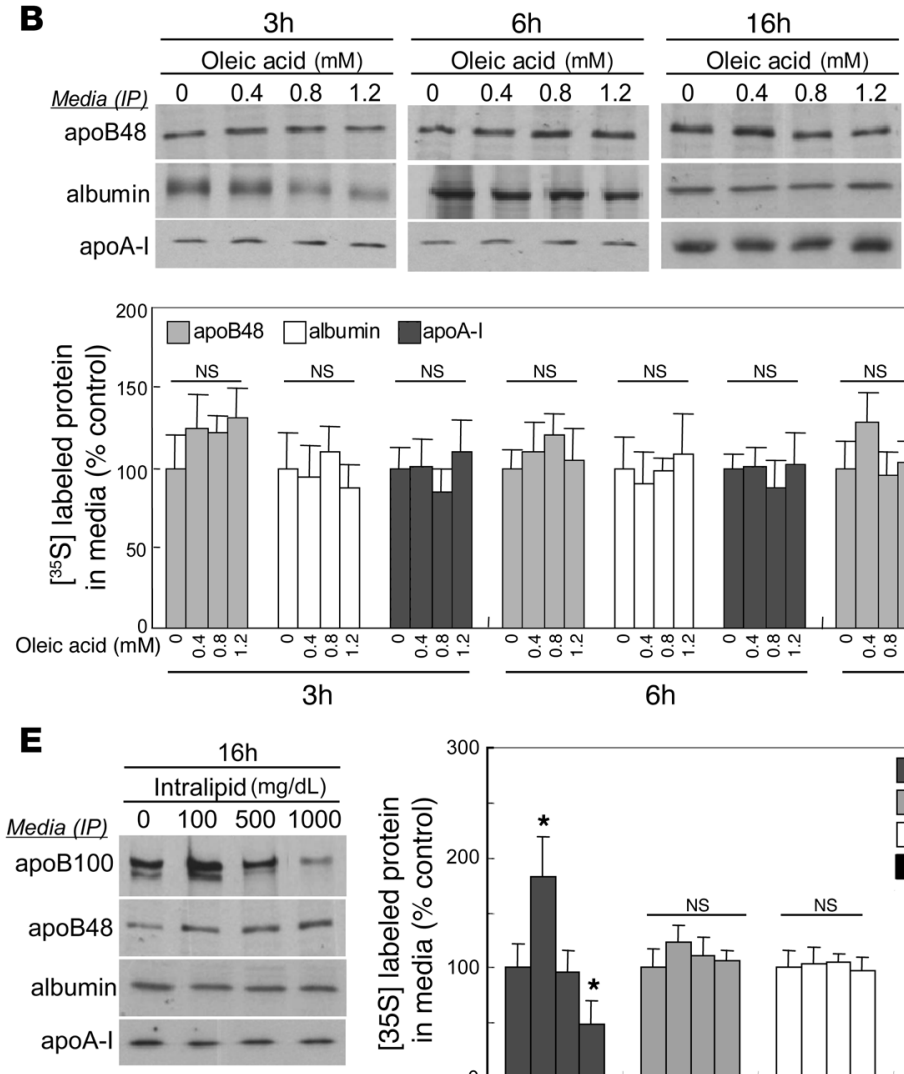

\section{Figure 5}

Lipid loading-induced ER stress has a parabolic effect on apoB100 secretion in McA cells. (A). McA cells were preincubated with $0.4,0.8$, or 1.2 $\mathrm{mM}$ of OA for 3,6 , or 16 hours, incubated for 2 hours in methionine/cysteine-free DMEM, and then labeled with [ ${ }^{35}$ S]methionine for 2 hours, the latter 2 incubations still in the presence of OA. There was a time and dose-dependent change from stimulation to inhibition of apoB100 secretion. (B) At the same doses, there were no effects of OA on the secretion of apoB48, apoA-I, or albumin at any duration of preincubation. (C) Using the same preincubation and incubation protocol, $1.6 \mathrm{mM}$ OA decreased apoB100, apoB48, albumin, and apoA-I secretion. (D) McA cells were preincubated with 100,500 , or $1,000 \mathrm{mg} / \mathrm{dl}$ IL for 16 hours, followed by the protocol described in A with IL present during the last 2 steps. There was a dose-dependent increase in ER stress, as indicated by increasing levels of GRP78 protein. (E) $100 \mathrm{mg} / \mathrm{dl}$ IL stimulated apoB100 secretion, whereas $500 \mathrm{mg} / \mathrm{dl}$ IL did not. Incubation with $1,000 \mathrm{mg} / \mathrm{dl}$ IL actually inhibited apoB100 secretion. Intralipid, at the doses used, had no effects on apoB48, albumin, or apoA-I secretion. (F) TCA precipitable radioactivity was unaffected at concentrations of $0.4,0.8$, or 1.2 mM OA. However, a 16-hour preincubation with $1.6 \mathrm{mM}$ OA did reduce TCA-precipitable radioactivity by about $30 \%$. None of the doses of IL that were used affected TCA-precipitable radioactivity. All data are mean \pm SD normalized to cells incubated without OA or IL ( $n=3$ for each condition); ${ }^{\star} P<0.05,{ }^{\star *} P<0.01$ versus control incubations. 
McA cells with PBA reversed the abnormality in the appearance of full-length apoB100 seen with $1.2 \mathrm{mM} \mathrm{OA}$ (Figure 9D).

Tunicamycin-induced ER stress inbibits apoB100 secretion. Tunicamycin, an inhibitor of glycosylation, is widely used to induce ER stress. In order to determine whether ER stress induced in the absence of increased delivery of FAs also affected apoB secretion, we treated McA cells with tunicamycin. Supplemental Figure 2A shows that tunicamycin, as expected, caused a dose-dependent rise in GRP78 and phospho-eIF2 $\alpha$ levels. These effects of tunicamycin were significantly inhibited by cotreatment with PBA. Concomitantly, tunicamycin dose-dependently inhibited apoB100 secretion (Supplemental Figure 2B), and this was also reversed by cotreatment with PBA at all except the highest dose of tunicamycin; PBA only partially reversed the effects of $5.0 \mu \mathrm{g} / \mathrm{ml}$ tunicamycin. Importantly, $0.2 \mu \mathrm{g} / \mathrm{ml}$ and $1.0 \mu \mathrm{g} / \mathrm{ml}$ of tunicamycin, which significantly inhibited apoB100 secretion, did not have any effect on secretion of apoB48, albumin, or apoA-I (Supplemental Figure $2 \mathrm{C})$. However, $5.0 \mu \mathrm{g} / \mathrm{ml}$ of tunicamycin inhibited secretion of all of these proteins, an effect that was reversed by PBA. Finally, total TCA-precipitable radioactivity was unaffected by 0.2 or $1.0 \mu \mathrm{g} / \mathrm{ml}$ of tunicamycin but was reduced about $30 \%$ by the $5.0-\mu \mathrm{g} / \mathrm{ml}$ dose. The latter effect was reversed by PBA. Trypan blue staining was normal at all doses of tunicamycin (data not shown).

Intravenous infusions of $6 \mathrm{mM}$ OA for 6 and 9 hours increase hepatic markers of ER stress. To assess the relationship between FA-induced ER stress and apoB secretion in vivo, we infused $6 \mathrm{mM}$ OA bound to albumin for either 6 or 9 hours into C57BL/6J mice to increase the amount of FAs delivered to the liver. OA infusions raised plasma FA levels to $0.87 \pm 0.33 \mathrm{mmol} / \mathrm{l}$ and to $1.20 \pm 0.75 \mathrm{mmol} / \mathrm{l}$ after 6 and 9 hours, respectively. These levels were significantly greater $(P<0.001)$ than those present during saline infusions $(0.39 \pm 0.12 \mathrm{mmol} / 1$ and $0.29 \pm 0.09 \mathrm{mmol} / 1$, respectively). At the end of 6- and 9-hour OA infusions, liver TG levels tended to be higher compared with saline infusions, but there were no significant differences observed (6-hour: $187 \pm 64$ vs. $138 \pm 46 \mu \mathrm{g} \mathrm{TG} / \mathrm{mg}$ protein; 9-hour: $275 \pm 169$ vs. $192 \pm 82 \mu \mathrm{g} \mathrm{TG} / \mathrm{mg}$ protein; both NS) (Figure 10A).

We next determined the levels of ER stress markers in the liver after 6-and 9-hour infusions of OA. After infusion of $6 \mathrm{mM}$ OA for 6 hours, GRP78 mRNA expression tended to increase compared with saline infusion $(151 \% \pm 85 \%$ vs. $100 \% \pm 30 \%$; NS); after 9 hours, however, we observed a significant, 1.8-fold increase in GRP78 mRNA expression $(180 \% \pm 52 \%$ vs. $100 \% \pm 26 \%$; $P<0.05$ ). After 6 -hour infusions of OA, GRP78 protein (Figure 10B) increased about 2 -fold compared with saline infusions $(192 \% \pm 104 \%$ vs. $100 \% \pm 17 \%$; $P<0.05)$; GRP78 protein increased by

\section{Figure 6}

Incubation of McA cells with OA or IL does not affect either $A p o b$ or Mttp mRNA levels. The effect of varying doses of OA (0.4-1.6 mM) or IL (100-1,000 mg/dl) on Apob (A) and $M t t p(B)$ expression in McA cells was assessed using quantitative real-time RT-PCR. Apob and Mttp mRNA levels were normalized with GAPDH mRNA. Apob and Mttp mRNA expression was unchanged by incubation with increasing doses of either OA or IL for 3-16 hours. Data are mean $\pm \operatorname{SD}$ ( $n=6$ for each condition). almost 3 -fold after 9-hour infusions $(288 \% \pm 126 \%$ vs. $100 \% \pm 49 \%$; $P<0.01)$. Compared with saline infusion, levels of phospho-eIF $2 \alpha$ increased about 2- to 2.5 -fold after both 6 -hour $(209 \% \pm 73 \%$ vs. $100 \% \pm 51 \% ; P<0.01)$ and 9 -hour infusions of OA $(231 \% \pm 83 \%$ vs. $100 \% \pm 68 \%$; $P<0.05$ ) (Figure 10C). Activation of XBP1 was determined by measuring the degree of processing of its mRNA $(28,29)$. XBP1 processing was increased at the end of both 6-hour $(123 \% \pm 11 \%$ vs. saline; $P<0.05)$ and 9 -hour $(152 \% \pm 31 \%$ vs. saline; $P<0.01)$ infusions, but the degree of processing tended to be greater after 9 hours (Figure 10D).

Intravenous infusions of $6 \mathrm{mM} \mathrm{OA}$ for 6 hours increases apoB secretion, but this effect is lost after 9-hour infusions. We previously reported that intravenous infusions of OA led to increased secretion of apoB without changes in TG secretion (35). In the present studies, we confirmed that finding: although (as noted above) there were significant elevations of plasma FAs by infusion of OA for either 6 or 9 hours, there were no increases in TG secretion after either infusion relative to infusions with saline (data not shown). We also confirmed our prior result that 6-hour infusions of OA increased secretion of newly synthesized apoB100 and apoB48 compared with saline infusion $(185 \% \pm 99 \%$ vs. $100 \% \pm 19 \%$ and $231 \% \pm 78 \%$ vs. $100 \% \pm 32 \%$, respectively; both $P<0.05$ ) (Figure 11A). By contrast, the stimulation of apoB secretion by 6-hour infusions of $\mathrm{OA}$ was not seen after 9-hour infusions of OA (Figure 11B). Indeed, secretion of newly synthesized apoB100 and apoB48 was essentially unchanged after 9-hour infusions of OA compared with saline. Based on our in vitro results and published data (34), we next pretreated mice for 7 days with PBA before infusing OA for 9 hours. PBA treatment was associated with significantly less OA-mediated ER stress, as indicated by reduced responses of
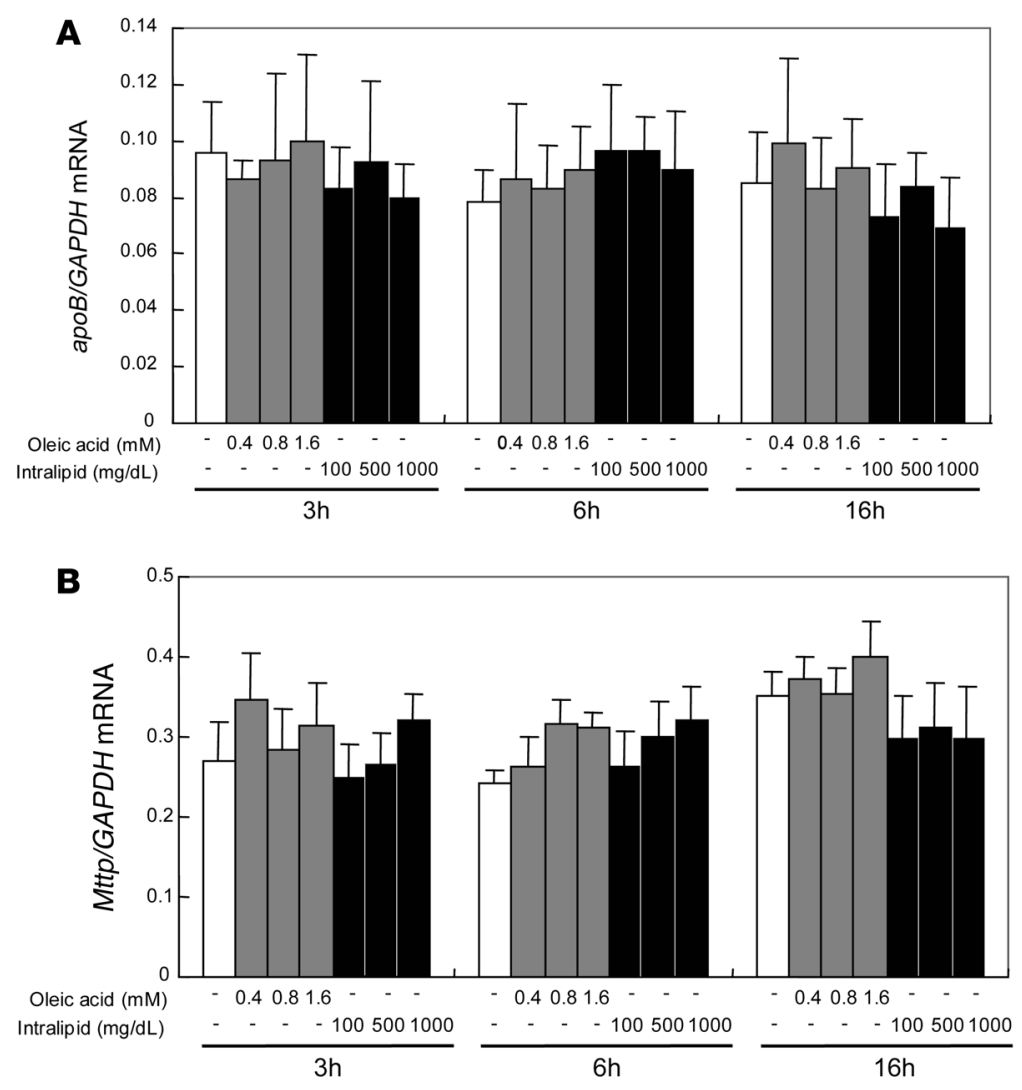


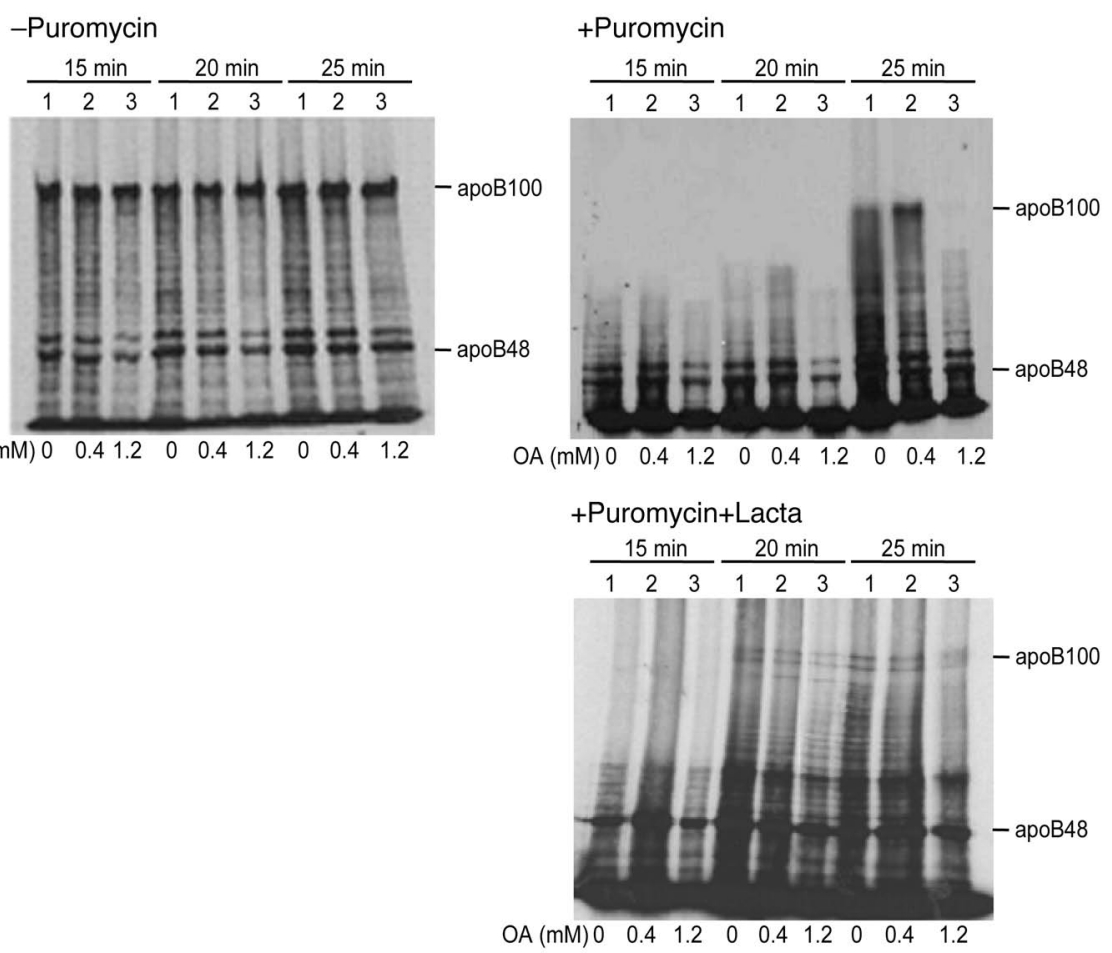

Figure 7

Prolonged incubation of McA cells with high-dose OA reduces the accumulation of full-length apoB100; this is reversed by cotreatment with lactacystin. McA cells were incubated for 16 hours with serum-free DMEM containing 1.5\% BSA (lane 1), 1.5\% BSA plus $0.4 \mathrm{mM}$ OA (lane 2), $1.5 \%$ BSA plus $1.2 \mathrm{mM}$ OA (lane 3 ); this was followed by an additional 10 minutes incubation, under the same 3 conditions, without (top left) or with $100 \mu \mathrm{M}$ puromycin. The puromycintreated cells were also incubated in the absence (top right) or presence (bottom right) of $10 \mu \mathrm{M}$ lactacystin (Lacta). The cells were then put on ice and the puromycin removed. The cells were transferred to $a 7^{\circ} \mathrm{C}$ water bath and labeled with serum-free, methionine/cysteine-free DMEM containing [ ${ }^{35}$ S]methionine for 15,20 , or 25 minutes. (The 2 latter steps were also performed with or without lactacystin.) $1.2 \mathrm{mM}$ OA inhibited the accumulation of full-length apoB100; lactacystin treatment (bottom right) significantly increased the accumulation of full-length apoB100 after incubation with $1.2 \mathrm{mM}$ OA for 16 hours (compare with top right). The data shown are representative of 2 experiments.

GRP78 and phospho-eIF2 $\alpha$ (data not shown). PBA treatment was also associated with increased secretion of apoB100; PBA-treated mice secreted twice as much apoB100 in response to OA as mice not treated with PBA $(203 \% \pm 36 \%$ vs. $116 \% \pm 43 \%$, respectively; $P<0.01$ ) (Figure 11C). We did not see any effect of PBA on secretion of apoB48 $(132 \% \pm 39 \%$ vs. $117 \% \pm 40 \%$, PBA-treated mice vs. non-treated mice, respectively). In these experiments, secretion of apoB100 and apoB48 in non-PBA-treated, saline-infused mice, was set at $100 \%$ (Figure 11C).

Intravenous infusions of 20\% Intralipid for 9 hours increases hepatic TG but does not stimulate either apoB or TG secretion. The quantity of FAs delivered to the liver during either 6- or 9-hour infusions of OA is very small (about $1.5 \mathrm{mg} / 6$ hours and $2.3 \mathrm{mg} / 9$ hours, respectively; ref. 35). Therefore, we conducted experiments in which $20 \%$ Intralipid was infused for 9 hours. In previous studies (35), infusions of $20 \%$ Intralipid for 6 hours (which delivered about $45 \mathrm{mg}$ FAs to the liver) did not increase hepatic TG mass significantly but did stimulate secretion of both TGs and apoB by about $100 \%$ (35). The results (Supplemental Figure 3) show that a 9-hour infusion of $20 \%$ Intralipid (which would deliver about $60 \mathrm{mg}$ FAs to the liver) increased hepatic TG mass by approximately $70 \%$ (Supplemental Figure $3 \mathrm{~A}$ ) but did not increase the secretion of TGs (Supplemental Figure 3B) or either apoB100 or apoB48 (Supplemental Figure 3C).

\section{Discussion}

Our goal in the present studies was to reconcile 2 well-described associations that we found inconsistent. First, it has been well demonstrated that IR is associated with increased assembly and secretion of both VLDL apoB and TGs in animal models and humans (36-38). The link between IR and increased VLDL secretion has been thought to derive from increased delivery of FAs to the liver secondary to increased lipolysis in adipose tissue; increased hepatic lipogenesis; increased levels and activity of MTP; and loss of insulin's ability to direct apoB toward degradation. Second, it is also clear that obesity, IR, and dyslipidemia frequently coexist with nonalcoholic steatosis (7-10). In view of the extensive body of evidence indicating that FAs and TGs can stimulate the assembly and secretion of VLDL $(18,39)$, one could question why the liver cannot maintain lipid homeostasis by increasing both the number of VLDL particles secreted and the quantity of TGs on each particle.

Recent studies implicating hepatic ER stress as a central abnormality linking obesity, hepatic IR, and hepatic steatosis have added a new level of complexity to this issue $(13,14,40)$. For example, ER stress has also been linked to increased hepatic lipogenesis $(23,41)$. Additionally, a large, complex secretory protein such as apoB might be a prime target for UPR-mediated downregulation. It is well known that apoB is regulated at translational and posttranslational steps, including a number of pathways for intracellular degradation (18-20). Thus, ER stress-mediated reductions in apoB secretion could be a link between ER stress and hepatic steatosis. On the other hand, Ozcan et al. demonstrated that obesity-induced ER stress led to hepatic IR through activation of JNK activity via inositol-requiring enzyme-1 (IRE-1), with subsequent inhibition of insulin receptor signaling (13). Although insulin has been shown to acutely inhibit hepatic secretion of apoB in both in vitro and in vivo studies (42-44), this effect is lost in animal models of hepatic IR $(45,46)$ and in obese subjects with chronic hyperinsulinemia (43, 47). Thus, ER stress-induced IR could actually increase the assembly and secretion of VLDL, thereby reducing the risk for steatosis.

Based on these complex and potentially discordant findings, we hypothesized that modest increases in the delivery of FAs to the liver and/or modest accumulation of hepatic lipids would increase apoB secretion despite some stimulation of ER stress, while more substantial accumulation of hepatic lipids would further increase 

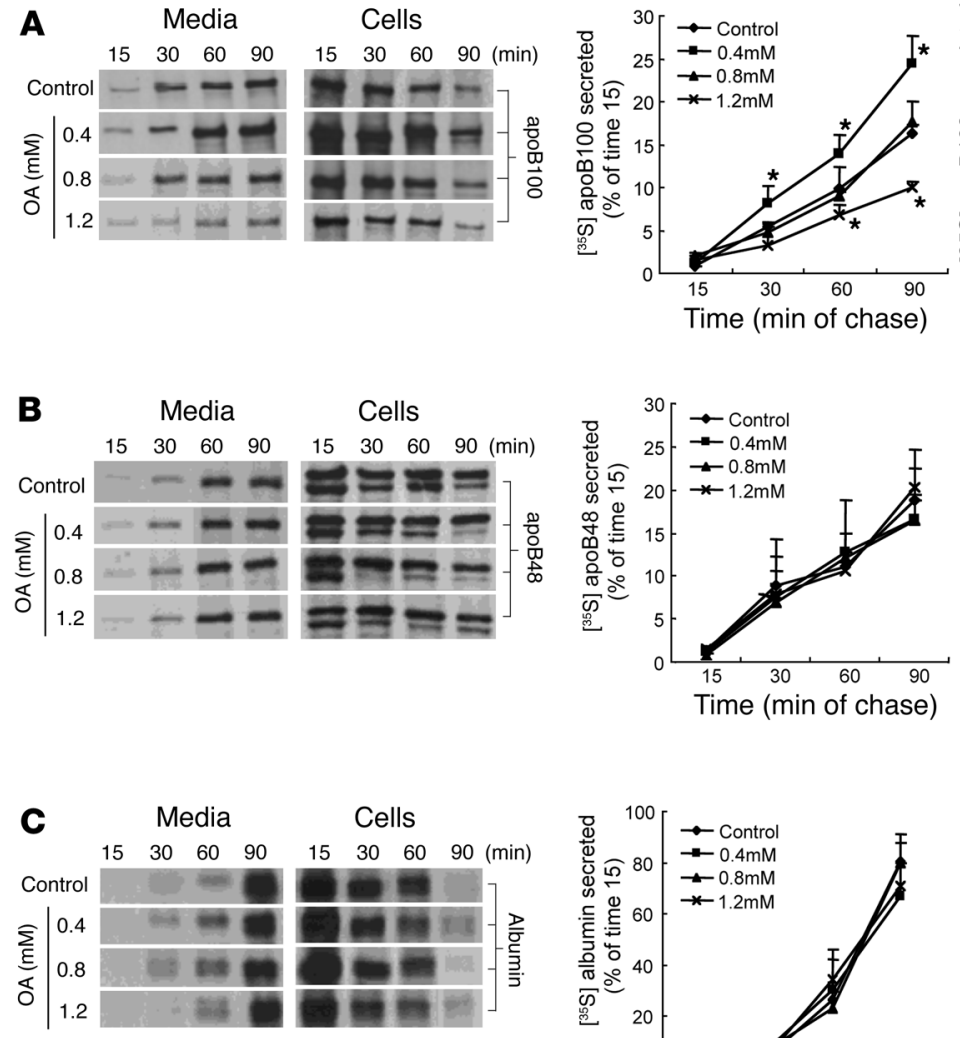

D

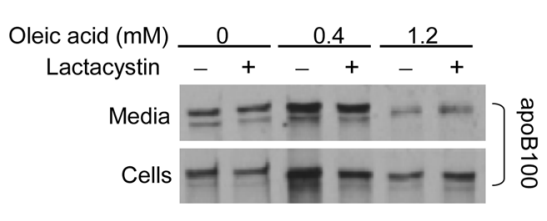

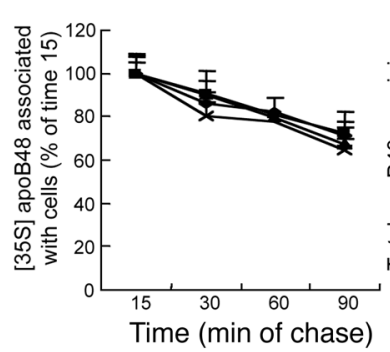
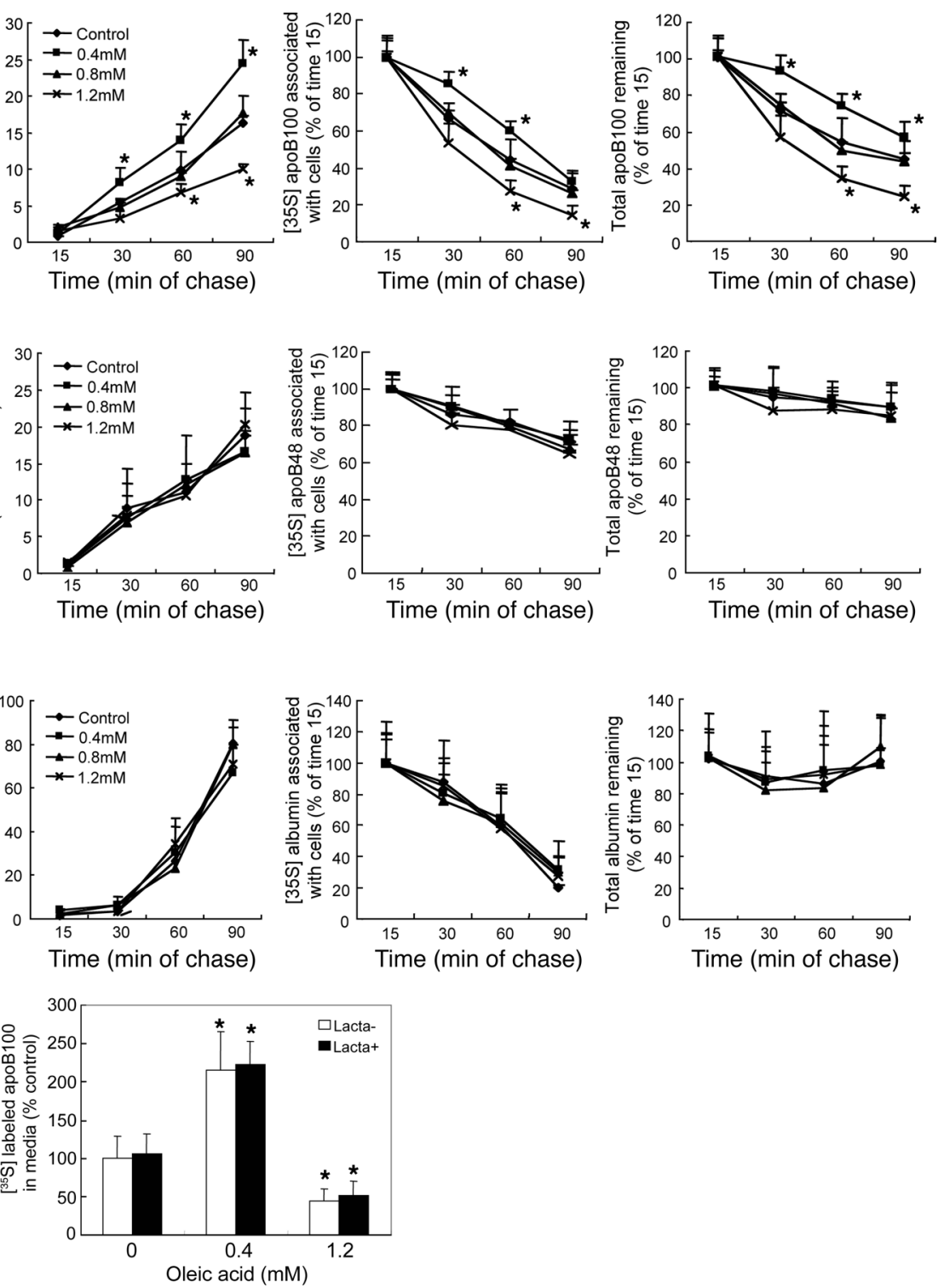

Figure 8

Incubation of McA cells with OA results in dose-related increases in intracellular degradation of apoB100 by nonproteasomal pathways. McA cells were incubated in the presence or absence of OA for 16 hours; cells were pulse labeled with [ ${ }^{35}$ S]methionine for 20 minutes and chased for 90 minutes. Samples were taken every 15 minutes and processed by immunoprecipitation and $4 \%$ SDS-PAGE. The quantity of protein in the cell lysates at the 15 -minute chase time point was taken as $100 \%$ of newly synthesized apoB100 (A), apoB48 (B), or albumin (C). Data are mean \pm SD normalized to cells incubated without OA. ${ }^{*} P<0.05$ vs. control; $n=3$ for each condition. Incubations with increasing concentrations of $\mathrm{OA}$ were associated with a parabolic effect on intracellular degradation and secretion of apoB100; there were no effects of increasing OA on degradation or secretion of apoB48 or albumin. (D). McA cells were incubated for 16 hours with no OA, $0.4 \mathrm{mM} \mathrm{OA,} \mathrm{or} 1.2 \mathrm{mM}$ OA in the absence or presence of lactacystin and then radiolabeled for 2 hours Lactacystin did not alter the parabolic effect of increasing concentrations of $\mathrm{OA}$ on apoB100 secretion.

ER stress, leading to reduced apoB secretion; i.e., there would be a parabolic relationship between lipid-induced ER stress and apoB secretion. We tested this hypothesis in both in vitro and in vivo systems and demonstrated that (a) increased FA delivery and/or accumulation of liver TGs (or intermediary metabolites) caused ER stress; and (b) although mild ER stress secondary to increased FA delivery was associated with increased secretion of apoB100, greater ER stress and/or the presence of ER stress for a longer period of time in response to increased FA delivery and/or TG accumu- lation resulted in reduced apoB100 secretion and greater hepatic steatosis. We discuss each of these findings below.

In mammals, the UPR is mediated through 3 distinct pathways that are under the control of PERK, activating transcription factor-6 (ATF-6), and IRE-1 $\alpha(3,17)$. To decrease the accumulation of proteins in the ER, the UPR attenuates translation, particularly of secretory proteins, via activation of PERK and subsequent phosphorylation of eIF2 $\alpha$ at Ser51. Additionally, the UPR increases the folding capacity of the ER by upregulating ER chaperones, such as 
A
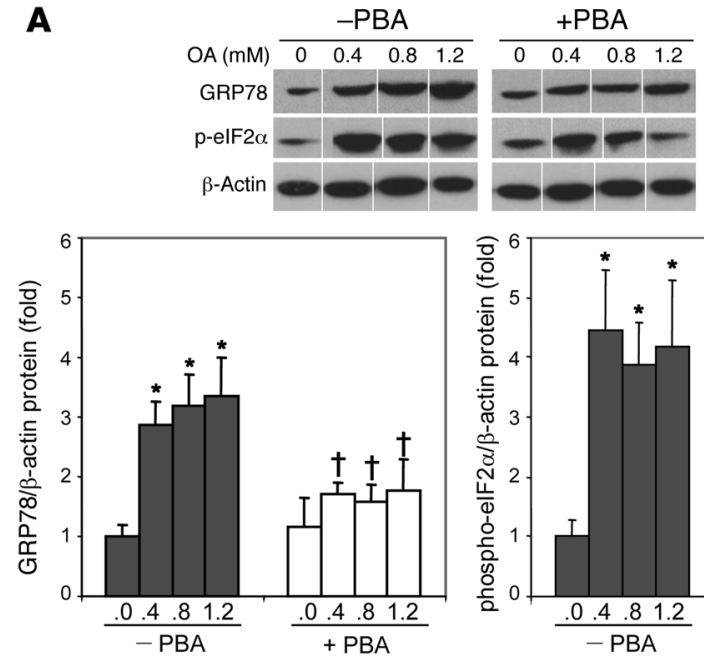

B

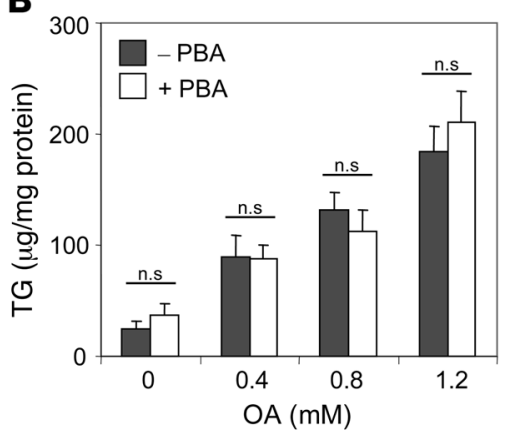

C
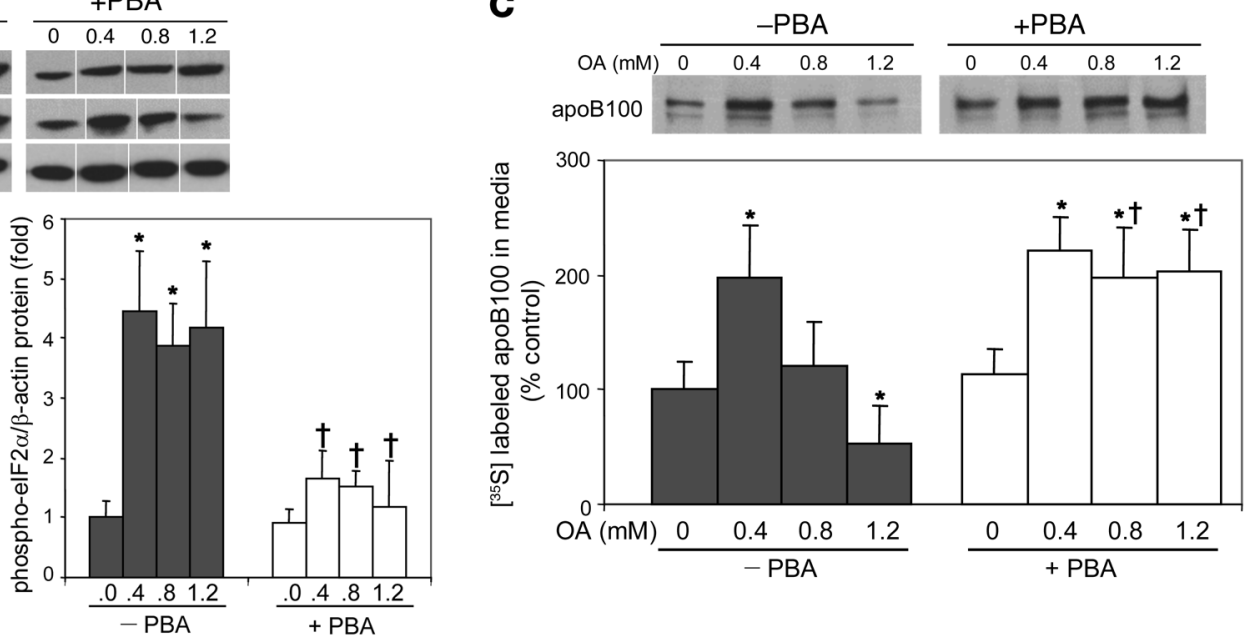

Figure 9

Treatment of McA cells with PBA inhibits ER stress and restores OA stimulation of apoB100 secretion. McA cells were incubated with or without PBA (1 mM) for 6 hours and then with or without PBA plus 0-1.2 mM OA for an additional 16 hours. (A) Incubations with OA increased GRP78 protein levels and the levels of phosphorylated elF2 $\alpha$, as analyzed by immunoblot; activation of these markers of ER stress was completely blocked by PBA. Lanes were run on the same gel but were noncontiguous. (B) Under these same conditions, coincubation of OA with PBA did not alter the ability of OA to increase cell TG content. (C) McA cells were incubated with or without PBA (1 mM) for 6 hours and were then incubated with or without PBA plus 0-1.2 mM OA for 16 hours, followed by methionine/cysteine-free DMEM for 2 hours and then [35S]methionine for 2 hours Increasing OA concentrations caused a rise and then a fall in apoB100 secretion (left); PBA treatment was associated with similar increases in apoB100 at all doses of OA (right). Data are mean $\pm \mathrm{SD} ; n=3$ per group. ${ }^{\star} P<0.05$ vs. incubations in the absence of both $\mathrm{OA}$ and $\mathrm{PBA} ;{ }^{\dagger} P<0.05$ vs. incubations with the same concentration of OA but without PBA. (D) McA cells were preincubated with serum-free DMEM with or without $1 \mathrm{mM}$ PBA for 6 hours and then incubated with serum-free DMEM containing no OA, 0.4 mM OA, or 1.2 mM OA for 16 hours, followed by an additional 10-minute incubation, under the same 3 conditions, with $100 \mu \mathrm{M}$ puromycin. After washing the cells free of puromycin while on ice, they were radiolabeled with [ ${ }^{35}$ S]methionine/cysteine in the DMEM for 15, 20, 25 minutes. PBA treatment (right) reversed the delayed appearance of full-length apoB100 translation seen after incubation with $1.2 \mathrm{mM}$ OA for 16 hours (left; also Figure 7 , top right).

GRP78, via the transcription factors XBP1 and ATF-6. Our data demonstrate that increased delivery of OA alone or FAs generated from Intralipid - which consists mainly of linoleic acid (54\%), OA (22\%), and palmitic acid (11\%) - to McA cells in vitro and to mouse liver in vivo triggered increases in the levels of GRP78 and activation of at least 2 branches of the UPR, PERK-eIF2 $\alpha$ and IRE1XBP1. Previous studies in pancreatic $\beta$ cells (48-50) and cardiac myoblasts (51) suggested that the ER stress was particularly sensitive to saturated FAs. Indeed, it has been reported that unsaturated FAs (OA or linoleate) reduce palmitate-induced upregulation of GRP78, CHOP, and GADD34, as well as apoptosis, in H4IIE liver cells (52). It has also been reported that hepatic steatosis caused by diets enriched in saturated FAs, but not polyunsaturated FAs, was associated with ER stress and liver injury despite similar accumulation of TGs with each diet (53). In the present studies, both OA and Intralipid were similarly effective in causing ER stress, both in vitro and in vivo (data for Intralipid in vivo not shown). We have conducted preliminary experiments with palmitic acid in McA cells and observed a similar ER stress response (data not shown). Further studies will be required to determine whether there are differential effects of FAs with varying degrees of saturation on apoB100 secretion in response to ER stress. It should be noted, however, that our incubations (16 hours) were longer than those in most other studies.

Identification of the molecular links between increased delivery of FAs to the liver and induction of ER stress will also require further study. Clearly, the stimulation of an ER stress response correlated closely with increases in the TG content of the McA cells in our in vitro incubation studies and, to a lesser degree, with increases in hepatic TG content in our in vivo studies. However, a 

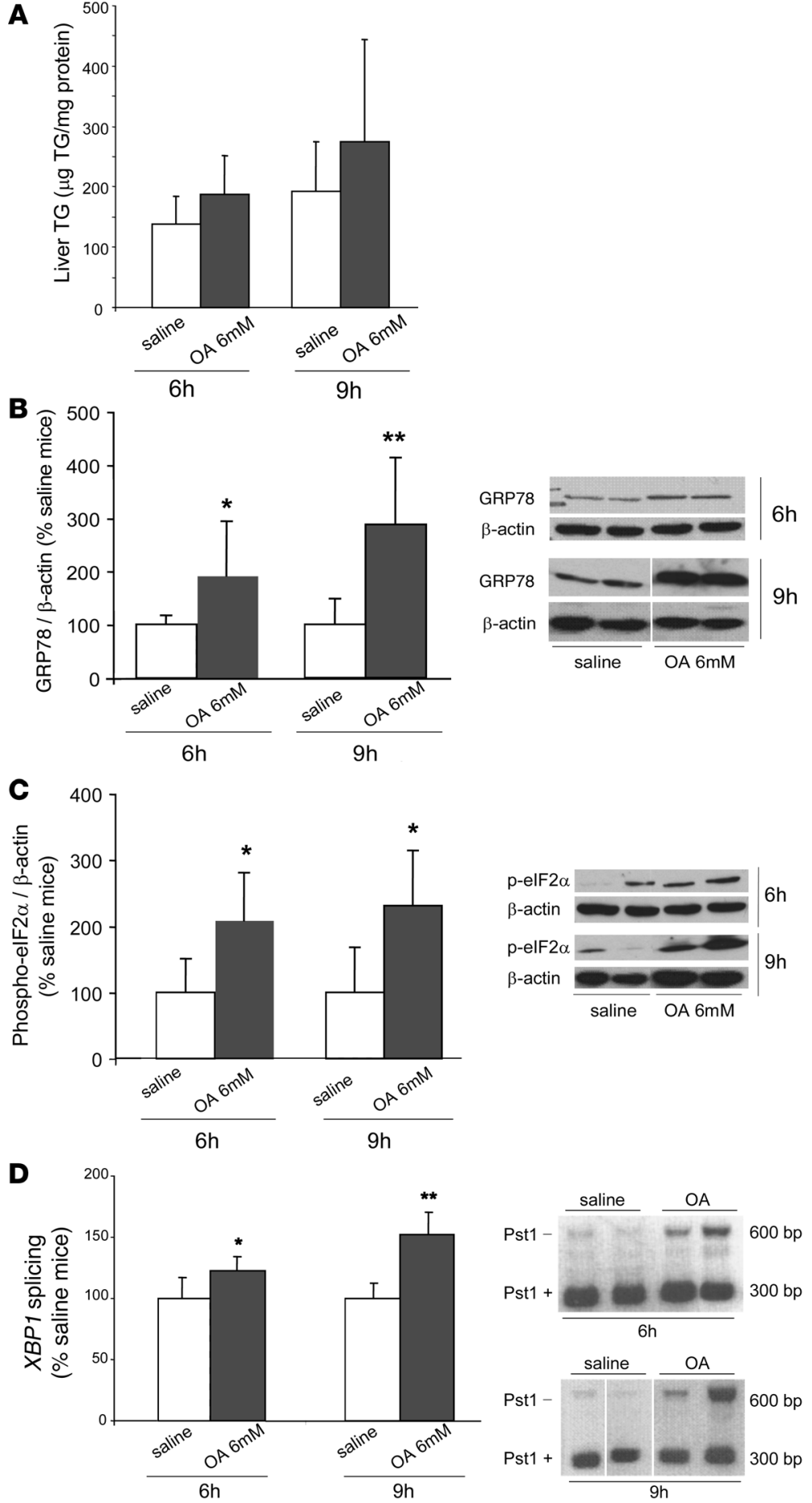

Figure 10

Intravenous infusions of $6 \mathrm{mM} \mathrm{OA}$ increase markers of hepatic ER stress in normal mice. C57BL/6J mice were infused intravenously with saline (white bars) or $6 \mathrm{mM}$ OA bound to albumin (gray bars) for 6 hours ( $n=9$ and 11 mice, respectively) or 9 hours ( $n=4$ mice/group). (A) At the end of 6- or 9-hour infusions, mice infused with $6 \mathrm{mM}$ $\mathrm{OA}$ and saline were sacrificed, and the livers were collected for the measurement of liver TG content. The mean values of liver TG content are expressed as micrograms of TG per milligram of liver total protein. After either 6- or 9-hour OA infusions, liver TG content tended to be higher compared with the saline infusion, but no significant differences were observed. Data are mean \pm SD. (B) The level of ER stress marker GRP78 was significantly increased by infusion of OA for either 6 hours or 9 hours compared with the levels present after infusion of saline. Lanes were run on the same gel but were noncontiguous. (C) Phosphorylation of elF2 $\alpha$ was significantly increased by infusion of OA for either 6 or 9 hours compared with levels present after infusion of saline. (D) Either 6- or 9-hour infusion of $6 \mathrm{mM}$ OA induced partial XBP1 mRNA splicing, indicative of the presence of ER stress in OA-infused compared with saline-infused mice. Lanes were run on the same gel but were noncontiguous. Data for B-D are mean \pm SD normalized to saline-infused mice. ${ }^{*} P<0.05$, ${ }^{\star \star} P<0.01$ versus saline.

$50 \%$, but we observed the same degree of OA-induced GRP78 expression and eIF2 $\alpha$ phosphorylation in McA cells (data not shown). These data provide support for the view that TG, per se, does not cause ER stress.

Many studies by our group and others have demonstrated increased secretion of apoB and TG in response to increased hepatic FAs and/or TGs (18). The effects of FAs/TGs are posttranscriptional; few physiologic perturbations alter Apob mRNA levels, although translation can be affected under certain circumstances (18). Overall, the availability of the core lipid ligands of apoB determines whether the protein is targeted for co- and posttranslational degradation or for secretion $(19,55-57)$. MTP clearly plays a key role in this process, probably by both transferring core lipids from the ER membrane to the amino-terminal of apoB and acting as a kinetic anchor after interacting directly with the amino-terminal of the nascent apoB as it enters the ER lumen (58). In the present experiments, we confirmed many prior studies that have demonstrated increased apoB100 secretion when McA cells are incubated with moderate concentrations of OA for short periods of time. In fact, with only 3-hour exposures, OA stimulated the secretion of apoB100 across a wide dose range. However, when we incubated the cells with $1.2 \mathrm{mM}$

previous study showed that loss of MTP in mouse hepatocytes (by either gene disruption or chemical inactivation), with concomitant inhibition of apoB secretion and marked accumulation of hepatic TGs, was not associated with the induction of typical markers of ER stress (54), suggesting that TG was not the offending molecular species. Furthermore, when we used an antisense oligonucleotide to inhibit the expression of acyl-coenzyme A:diacylglycerol acyltransferase 2 (DGAT2), a key enzyme that catalyzes the last step in mammalian TG synthesis, TG accumulation was reduced by
OA for 6 hours, there was a loss of stimulation of apoB100 secretion, and this was paralleled by increased GRP78 under those same conditions. Finally, when we incubated McA cells for 16 hours, we observed a parabolic relationship between OA concentrations and apoB100 secretion. Of note, 16-hour incubations were associated with increases in ER stress markers at all concentrations of OA (data shown for GRP78), including $0.4 \mathrm{mM} \mathrm{OA}$ (shown for eIF2 $\alpha$ and XBP1). The parabolic relationship between FA-induced ER stress and apoB100 secretion was also observed with IL. Of note, 


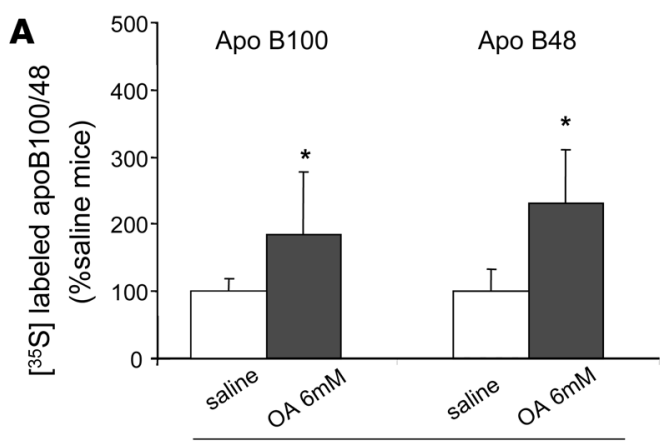

$6 \mathrm{~h}$

B

\section{B}

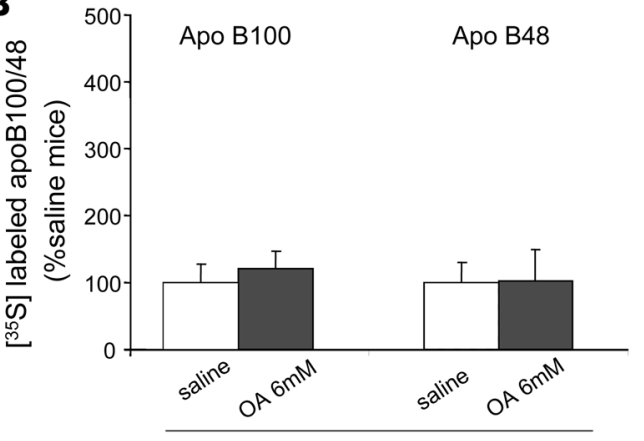

$9 \mathrm{~h}$

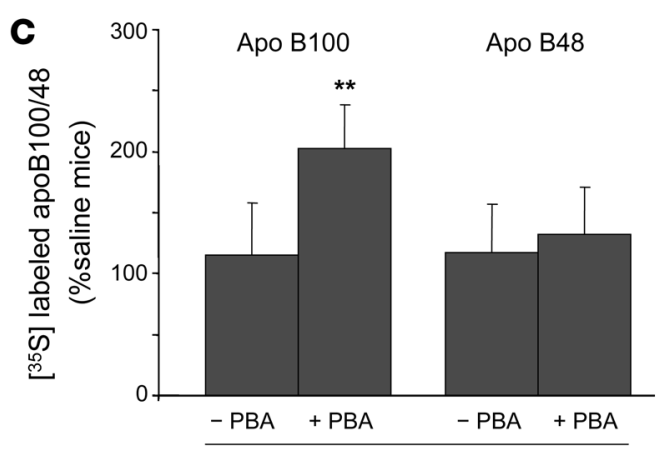

$9 \mathrm{~h}$

with both approaches to lipid delivery, inhibition of apoB100 occurred without any changes in the secretion of apoB48, albumin, or apoA-I from McA cells. It was only when the cells were exposed to $\mathrm{OA}$ at a concentration of $1.6 \mathrm{mM}$ for 16 hours that we observed inhibition of the secretion of all 4 proteins tested (we did not test IL at concentrations greater than $1,000 \mathrm{mg} / \mathrm{dl}$ ). These data suggest that at doses of OA below $1.6 \mathrm{mM}$, and at doses of IL up to $1,000 \mathrm{mg} / \mathrm{dl}$, the degree of ER stress was relatively mild and the global effects of ER stress on gene expression and translation of mRNA had not yet occurred. This view is supported by our finding that total TCA-precipitable radioactivity was reduced only when cells were exposed to $1.6 \mathrm{mM}$ OA for 16 hours, a perturbation that inhibited secretion of all 4 proteins tested. On the other hand, trypan blue staining was unchanged at all doses of OA and IL, indicating that lipid loading did not, in these experiments, induce generalized cell toxicity. It is clear from these data that apoB100, a protein that is extensively regulated by intracellular degradation $(19,55-57)$, is particularly sensitive to FA-induced ER stress. However, when the level of ER stress was further increased, the expected generalized effects of the UPR were demonstrated in

\section{Figure 11}

Stimulation of the secretion of apoB100 by 6 -hour infusions of $6 \mathrm{mM}$ $O A$ is lost after infusion of $O A$ for 9 hours but rescued after pretreatment of mice with PBA. C57BL/6J mice were infused with saline (white bars) or $6 \mathrm{mM} \mathrm{OA}$ in albumin (gray bars) intravenously for 6 or 9 hours, and both Triton WR1339 and [ ${ }^{35}$ S]methionine were injected into the mice at the end of each infusion to measure the secretion of newly synthesized apoB48 and apoB100. (A) Infusion of OA for 6 hours significantly increased the secretion of both apoB100 and apoB48 secretion into the bloodstream 1 hour after Triton injection compared with saline. (B) Infusion of OA for 9 hours did not increase either apoB100 or apoB48 secretion compared with saline. (C) PBA or water was administered orally to C57BL/6J mice for 7 days. After 9 hours of OA infusion, the PBA-treated mice showed an increase in apoB100 secretion compared with the nontreated mice. Data are mean \pm SD normalized to saline-infused livers (for 6-hour infusions: $n=9$ and 11 for saline and OA, respectively; for 9-hour infusions: $n=4 /$ group; for 9-hour infusion with or without PBA: $n=6$ /group). ${ }^{*} P<0.05$ versus saline; ${ }^{* *} P<0.01$ versus without PBA treatment.

our studies. Sparks et al. (59) showed inhibition of apoB secretion from McA cells incubated for 8 hours with $0.75 \mathrm{mM}$ OA. Furthermore, they demonstrated that the reduced apoB secretion was not associated with changes in Apob gene expression. They did not, however, look at other doses of OA, and there were no measurements of ER stress.

As reviewed above, the UPR includes pathways that increase the transcription of chaperone proteins and decrease the translation of secretory proteins $(3,17)$. Therefore, we first looked at the expression of 2 genes, Apob and Mttp, that obviously can affect apoB secretion: We saw no effect of lipid-induced ER stress on the mRNA levels of either Apob or Mttp. However, when we looked at posttranscriptional steps regulating apoB synthesis and secretion, we found clear evidence for complexity.

First, our studies with puromycin-synchronized cells, with and without concomitant lactacystin, indicated that both reduced rates of elongation of nascent apoB and cotranslational proteasomal degradation were affecting the appearance of full-length apoB100. The ability of lactacystin to significantly increase the appearance of apoB100 suggests that cotranslational ubiquitinylation and proteasomal degradation of apoB was the more significant process affecting the appearance of newly synthesized full-length apoB100 (60). Importantly, cotranslational ubiquitinylation of apoB100 does not become significant until about $40 \%-50 \%$ of the nascent protein has been translated (60). Thus, apoB48 would be much less likely to be polyubiquitinylated and targeted for proteasomal degradation. Similarly, small proteins such as albumin and apoA-I would likely escape ubiquitinylation. Future studies, using constructs of apoB of varying size and amino acid sequence, should provide further insights into the link between mild ER stress and cotranslational degradation of apoB100. In addition, despite the absence of change in Mttp mRNA levels, further studies will be needed to determine whether MTP function, which is key to the assembly and secretion of apoB-Lps, is altered by ER stress.

Lactacystin, however, did not completely reverse the reduced appearance of apoB100 in cells incubated with high concentrations of OA, suggesting reduced rates of translation. We had previously seen reduced translation of apoB100 when cotranslational lipidation was inhibited (61). Furthermore, a recent study by Borradaile et al. (51) implicated eukaryotic elongation factor (eEF1A) in FA-induced lipotoxicity; disruption of the gene protected cells. Although those 
authors did not demonstrate reduced protein synthesis in cells with disrupted eEF1A, those results raise the possibility that reduced elongation might be a response to FA-induced ER stress. Further studies are planned to address this question directly.

In addition to the cotranslational, proteasomal degradation we observed, we also demonstrated nonproteasomal, likely posttranslocational intracellular degradation of apoB100 in association with ER stress. Importantly, the pattern of increased degradation mimicked exactly the parabolic secretory pattern we observed. Qiu et al. reported that treatment of HepG2 cells with glucosamine resulted in elevated levels of GRP78 and reduced rates of secretion of apoB100, the latter due to increases in both proteasomal and nonproteasomal degradation of apoB100 $(26,62)$. Similar results were observed by that group when GRP78 was overexpressed by adenovirus, suggesting a direct effect of an increase quantity of this chaperone in targeting of apoB100 for proteasomal degradation (26). Oyadomari et al. found that P58 ${ }^{\mathrm{IPK}}$, an ER-associated protein whose synthesis is stimulated by ER stress, is a mediator of proteasomal degradation of newly synthesized apoB100 (63). Those authors found that the increase in proteasomal degradation of apoB100 induced by inhibition of MTP was attenuated in P58 $8^{\mathrm{IPK}-/-}$ hepatocytes, suggesting that P58 $8^{\mathrm{IPK}}$ is required for degradation of misfolded apoB associated with impaired lipidation. Further studies will be required to determine the exact roles, if any, of increased GRP78 and P58 IPK in the stimulation of apoB100 degradation we have observed. Of note, lactacystin did not alter ER stress-induced inhibition of apoB100 secretion when studied over a 2-hour period of radiolabeling. This was in contrast to the reversal of cotranslational degradation we observed in very short radiolabeling studies in puromycin-synchronized cells. We believe that together, these results indicate that nonproteasomal, posttranslocational pathways of degradation play a greater role in the overall response to ER stress than does cotranslational degradation. A recent study demonstrating that proteasomal degradation is transiently inhibited during the UPR adds further complexity to any interpretation of these findings (64). The exact site of the intracellular degradation of apoB100 during ER stress remains to be determined (31). However, the absence of any effects of either vitamin $\mathrm{E}$ or desferrioxamine on ER stress-associated inhibition of apoB100 secretion (32) indicates that lipid peroxidation and/or reactive oxygen species did not play a significant role. Finally, it is also noteworthy that we demonstrated increased intracellular degradation of nascent apoB100 despite finding evidence for activation of JNK and subsequent serine phosphorylation of IRS-1, indicative of ER stress-induced hepatic IR (data not shown). As noted above, diminished insulin signaling would be expected to lead to reduced degradation of apoB100 and increased secretion $(43,45,46)$.

PBA has been shown to be a chemical chaperone that stabilizes protein folding $(33,65)$. Recently, Ozcan et al., reported that treatment with the chemical chaperones PBA and taurine-conjugated ursodeoxycholic acid alleviated ER stress in cultured liver cells and $o b / o b$ mice (34). Those authors showed that PBA improved insulin action, leading to normalization of both glucose intolerance and steatosis in genetic and diet-induced mouse models of obesity. In that study (34), PBA attenuated the induction of ER stress by tunicamycin in Fao rat hepatoma cells. PBA has also been shown to improve the trafficking of mutant proteins in cystic fibrosis (CFTR $\triangle 508$ ) (66) and to enhance the secretion of $\alpha 1$-AT in $\alpha 1$-AT deficiency (67). In our study, PBA blocked lipid-induced ER stress in McA cells and specifically reversed the inhibition of apoB100 secretion by higher concentrations of OA, at least in part by normalizing the translation of apoB100 and/or protecting it from cotranslational degradation.

FA loading causes many cellular responses, including ER stress, raising the question of whether there is a direct link between FA-associated ER stress and inhibition of apoB100 secretion. Indeed, PBA, which we used to support such a direct link, has been shown to stimulate FA oxidation and have additional effects on cellular lipid metabolism (68). However, in our studies, PBA did not affect cellular TG content, suggesting that this chemical chaperone directly prevents the decrease in apoB100 secretion by inhibiting lipid-induced ER stress. More importantly, we have recapitulated nearly all the effects of FA loading on apoB100 secretion by using tunicamycin, a well-established inducer of ER stress. Thus, although tunicamycin did not, at any dose, stimulate apoB100 secretion, it did inhibit apoB100 secretion in a dosedependent manner that paralleled its effects on ER stress markers. Furthermore, tunicamycin showed the same "relative selectivity" for apoB100 that we observed with OA and IL; it was only at the $5-\mu \mathrm{g} / \mathrm{ml}$ dose of tunicamycin that secretion of apoB48, albumin, and apoA-I were inhibited. Finally, PBA reversed not only (as expected) tunicamycin-mediated ER stress, but also the inhibition of apoB100 secretion.

We had previously reported that in vivo exposure of mouse livers to high concentrations of FA for 6 hours resulted in significant increases in the secretion of apoB100 and apoB48 (35). In the present study, we confirmed that finding and further demonstrated that longer infusions of $\mathrm{OA}$ ( 9 hours) were associated with the loss of OA-stimulated apoB secretion; this loss of FA-stimulated apoB secretion was paralleled by increased and/or prolonged hepatic ER stress. Importantly, when we treated mice with PBA for 7 days, we reduced OA-mediated ER stress and rescued apoB100 from the effects of 9 hours of elevated FA levels. However, neither 6- nor 9-hour infusions of OA significantly increased liver TGs, so we also infused $20 \%$ Intralipid. Although our previous studies showed that 6-hour infusions of Intralipid stimulated both TG and apoB secretion without significantly increasing hepatic TG content (35), we found, in the present studies, that 9-hour infusions of $20 \%$ Intralipid did not stimulate TG and apoB secretion despite significantly increasing hepatic TG mass. These in vivo results confirm our in vitro studies and provide strong evidence directly implicating ER stress as the basis for the inhibition of apoB100 secretion during prolonged exposure of livers to high concentrations of FAs. Although 9-hour infusions of OA also led to the loss of FA-stimulated apoB48 secretion (Figure 11B), that abnormality was not reversed by PBA treatment. Further experiments will be needed to determine the differences we have observed between the in vitro and in vivo effects of ER stress and PBA on apoB48 metabolism.

The results of these studies provide new and novel insights into the pathophysiology of steatosis and hypertriglyceridemia, a combination of abnormalities characteristic of animal models and humans with IR. As noted above, a substantial proportion of individuals with IR have both hepatic steatosis and hyperlipidemia. Furthermore, the severity of hepatic steatosis correlates with secretion of increased numbers of large, TG-rich VLDL (69). Finally, it has been repeatedly demonstrated, both in vitro and in vivo (18, $35,39)$, that increased FA delivery to hepatocytes stimulates VLDL apoB and TG secretion. Together, those results raise a key question: why can't lipid-loaded livers, which are typically also insulin resistant, secrete as much VLDL as is necessary to avoid steatosis. 
The results we present demonstrate that lipid-induced hepatic ER stress can explain why steatosis develops despite increased VLDL secretion. The parabolic relationship between the degree of lipidinduced ER stress and apoB100 secretion suggests that in most animals and people with lipid-induced steatosis, VLDL secretion may be increased above normal, consistent with existing literature, but secretion will be less than maximal (on the downside of the parabola) due to excessive ER stress. Further studies will be required to determine both the molecular basis for FA-induced ER stress and for the increase in intracellular degradation of apoB. Of interest, our findings suggest that pharmacologic approaches directly targeting hepatic ER stress could be a therapy for steatosis, albeit at the expense of increased secretion of atherogenic apoB-Lps.

\section{Methods}

Growth of cells. McA cells were obtained from ATCC. McA cells were maintained in DMEM containing penicillin $(100 \mathrm{U} / \mathrm{ml})$, streptomycin $(100 \mu \mathrm{g} /$ $\mathrm{ml}$ ), 10\% FBS, and 10\% horse serum (Invitrogen).

Cell studies. For steady-state studies, McA cells were incubated for 0-48 hours in DMEM containing OA $(0.1-2.0 \mathrm{mM})$ bound to $1.5 \% \mathrm{BSA}$ or a mixture of Intralipid (10-1,000 mg/dl) (Abbott Laboratories) plus purified lipoprotein lipase $(\mathrm{LpL})(1 \mu \mathrm{g} / \mathrm{ml})$. When apoB metabolism was being studied, cells were further incubated in methionine/cysteine-free DMEM for an additional 2 hours and then labeled with $\left[{ }^{35} \mathrm{~S}\right]$ methionine for 2 hours. The latter 2 incubations were also in the absence or presence of varying concentrations of OA or IL. After labeling, media were transferred to tubes containing a mixture of protease inhibitors $(30 \mu \mathrm{l} / \mathrm{ml}$ protease inhibitors, $1 \mathrm{mM}$ benzamidine, $5 \mathrm{mM}$ EDTA, $100 \mathrm{U} / \mathrm{ml}$ aprotinin, $50 \mu \mathrm{g} / \mathrm{ml}$ leupeptin, $50 \mu \mathrm{g} / \mathrm{ml}$ pepstatin A, and $10 \mathrm{mM}$ HEPES, $\mathrm{pH} 8.0$ ) and $0.86 \mathrm{mM}$ freshly added phenylmethylsulfonyl fluoride. Cells were harvested with homogenization buffer $(62.5 \mathrm{mM}$ sucrose, $0.5 \%$ sodium deoxycholate, $0.5 \%$ Triton X-100, 50 mM Tris-HCl, pH 7.4, 150 $\mathrm{mM} \mathrm{NaCl}$, and protease inhibitors). Studies of intracellular degradation of apoB in McA cells involved incubation with various concentrations of OA for 16 hours followed by an additional incubation with methionine/cysteine-free DMEM containing 1.5\% BSA for 2 hours, pulse labeling with $\left[{ }^{35} \mathrm{~S}\right]$ methionine for 20 minutes, and a 90-minute chase protocol in medium supplemented with cold methionine. Samples were taken every 15 minutes during the chase and processed for medium and intracellular apoB by immunoprecipitation and SDS-PAGE as described below. The effect of OA or IL at any concentration on cell viability or total protein synthesis was measured by TCA-precipitable radioactivity. To determine whether proteasomal degradation of apoB was increased by ER stress, McA cells were treated with OA for 16 hours and in methionine/cysteinefree DMEM for 2 hours, before being radiolabeled with $\left[{ }^{35} \mathrm{~S}\right]$ methionine for 2 hours in the presence or absence of lactacystin $(10 \mu \mathrm{M})$.

Puromycin synchronization of $M c A$ cells. To determine the effect of ER stress on the rate of translation of apoB, McA cells were preincubated with serum-free DMEM containing $1.5 \% \mathrm{BSA}$, BSA and $0.4 \mathrm{mM} O \mathrm{OA}$, and BSA and $1.2 \mathrm{mM}$ OA for 16 hours, followed by an additional 10-minute incubation, under the same 3 conditions, with $100 \mu \mathrm{M}$ puromycin, which synchronizes polysome formation and translation. The cells were then put on ice and washed with ice-cold PBS 3 times in an ice bath to remove the puromycin. The cells were then transferred to a $37^{\circ} \mathrm{C}$ water bath and labeled with serum-free, methionine/cysteine-free DMEM containing $\left[{ }^{35} \mathrm{~S}\right]$ methionine $(150 \mu \mathrm{Ci} / \mathrm{ml})$ for 15,20 , or 25 minutes. In some experiments, all of these steps were performed in the absence or presence of PBA. After radiolabeling, cellular lysates were subjected to immunoprecipitation with antisera to apoB, and the resolubilized immunoprecipitate was separated on $4 \%$ SDS-PAGE.
PBA treatment of McA cells. PBA is known to stabilize protein conformation, improve the folding capacity of proteins in the ER, and protect against ER stress $(33,34)$. McA cells were preincubated with serum-free DMEM containing $1 \mathrm{mM}$ PBA for 6 hours and then incubated with OA for 16 hours. The cells were then incubated in methionine/cysteine-free DMEM for 2 hour, and finally labeled with $\left[{ }^{35} \mathrm{~S}\right]$ methionine for 2 hours. All 3 latter steps were performed in the presence of PBA. Immunoprecipitation of apoB, apoA-I, or albumin in medium or cellular lysate was carried out. In parallel experiments using the same conditions, cells were lysed and analyzed by immunoblotting for GRP78 and for phosphorylation of eIF2 $\alpha$. Other cells were extracted, and cellular TG mass was measured.

Immunoprecipitation. Immunoprecipitation of apoB, apoA-I, or albumin in medium or cellular lysate was carried out according to the method of Dixon et al. (55). The antibodies used were goat anti-human apoB, goat anti-human apoA-I (Calbiochem), and anti-human albumin (SigmaAldrich). rProtein G Agarose (Invitrogen) was added to the reaction solution to precipitate apoB, which was released with sample buffer $(0.125 \mathrm{M}$ Tris- $\mathrm{HCl}$, pH 6.8, 4\% SDS, $20 \%$ glycerol, and $10 \% \beta$-mercaptoethanol) by boiling for 5 minutes. Samples were resolved by SDS-PAGE. The gel was treated with Autofluor (National Diagnostics) and, after drying, exposed to $\mathrm{x}$-ray film (X-Omat AR; Kodak) at $-80^{\circ} \mathrm{C}$ and quantified as incorporation of $\left[{ }^{35} \mathrm{~S}\right]$ into apoB48 and apoB100 by autoradiography.

Lipid extraction and cell $T G$ and protein mass determination. For lipid extraction, cells were washed with PBS and then extracted twice with hexane/isopropanol (3:2, vol/vol) $(2 \mathrm{ml} /$ well $)$ at room temperature for 30 minutes. The extraction solution was collected and dried under a stream of $\mathrm{N}_{2}$ gas, and the remaining cellular proteins were lysed with $0.1 \mathrm{~N} \mathrm{NaOH}$. TG mass in cell extracts was determined using a TG determination kit (Trig/GB; Roche Diagnostics). Cellular protein levels were determined with a BCA kit (Pierce).

Immunoblots. After in vitro treatment of McA cells with OA, IL, or tunicamycin $(5 \mu \mathrm{g} / \mathrm{ml})$, cells were washed twice with PBS, lysed using either SDS buffer (2\% SDS, 62.5 mM Tris- $\mathrm{HCl}$ [pH 6.8], 10\% glycerol, $50 \mathrm{mM} \mathrm{DTT}$, and $0.01 \%$ bromophenol blue) or homogenization buffer $(62.5 \mathrm{mM}$ sucrose, $0.5 \%$ sodium deoxycholate, $0.5 \%$ Triton $\mathrm{X}-100,50 \mathrm{mM}$ Tris- $\mathrm{HCl}, \mathrm{pH} 7.4$, $150 \mathrm{mM} \mathrm{NaCl}$, and protease inhibitors) and then boiled at $100^{\circ} \mathrm{C}$ for 5 minutes. At the end of the in vivo experiments, mice were sacrificed, and liver samples were collected and snap frozen. Protein extracts were prepared with a lysis buffer containing $25 \mathrm{mM}$ Tris- $\mathrm{HCl}$ ( $\mathrm{pH} 7.4$ ), $2 \mathrm{mM} \mathrm{Na}_{3} \mathrm{VO}_{4}, 10$ $\mathrm{mM} \mathrm{NaF}, 10 \mathrm{mM} \mathrm{Na}_{4} \mathrm{P}_{2} \mathrm{O}_{7}, 1 \mathrm{mM}$ EGTA, 1 mM EDTA, 1\% NP-40, $5 \mu \mathrm{g} / \mathrm{ml}$ leupeptin, $5 \mu \mathrm{g} / \mathrm{ml}$ aprotinin, $10 \mathrm{nM}$ okadaic acid, and $1 \mathrm{mM}$ PMSF. Equal amounts of protein extracts were separated on a 10\% SDS-PAGE gel and electrotransferred to $0.45-\mu \mathrm{m}$ nitrocellulose membrane using a Bio-Rad mini-transfer tank. Membranes were incubated with primary antibodies overnight, and the protein bands were detected with HRP-conjugated secondary antibodies and SuperSignal West Pico enhanced chemiluminescent solution (Pierce). Membranes were stripped with Restore Western Blot Stripping Buffer (Pierce) for 15 minutes at room temperature and reprobed with antibodies to $\beta$-actin to control for differences in loading. The primary antibodies used were anti-GRP78, anti-phospho-eIF2 $\alpha$ (Stressgen), eIF2 $\alpha$ (Cell Signaling), and monoclonal anti- $\beta$-actin (Sigma-Aldrich).

Analysis of XBP1 processing. McA cells were exposed to OA, IL, or tunicamycin, and XBP1 cDNA encompassing the region of restriction site was amplified by PCR using previously described primers (28). The PCR product was incubated with the Pst 1 restriction enzyme for 5 hours at $37^{\circ} \mathrm{C}$, followed by separation of the restriction digests on a $2 \%$ agarose gel with ethidium bromide. The gels were photographed under UV transillumination and quantified by densitometry. The amount of 601-bp material (indicative of XBP1 activation and thus of ER stress) was expressed as a percentage of the total amount of amplified material, considering the sum of the 2 bands in each lane as $100 \%$. 


\section{Table 1}

Primer sequences for real-time PCR

\begin{tabular}{|c|c|c|c|}
\hline Gene & Primers & Primer sequence & GenBank no. \\
\hline \multirow[t]{2}{*}{ GRP78 } & $5^{\prime}$ & 5'-CCACCAGGATGCAGACATTG-3' & S63521 \\
\hline & $3^{\prime}$ & 5'-AGGGCCTCCACTTCCATAGA-3' & \\
\hline \multirow[t]{2}{*}{ Apob } & $5^{\prime}$ & 5'-ATGTCACGTGGAGCACTGGT-3' & NM_019287 \\
\hline & $3^{\prime}$ & 5'-TCTCССТССАAGTCCCAAAG-3' & \\
\hline \multirow[t]{2}{*}{ Mttp } & $5^{\prime}$ & 5'-AAATCGGGTGGCTGTGGTAA-3' & XM227765 \\
\hline & $3^{\prime}$ & 5'-ATCCGGGCACTAGGCTCTCT-3' & \\
\hline \multirow[t]{2}{*}{ GAPDH } & $5^{\prime}$ & 5'-GGCAAGTTCAATGGCACA-3' & M17701 \\
\hline & $3^{\prime}$ & 5'-AGCACCAGCATCACCCCATTT-3' & \\
\hline \multirow[t]{2}{*}{ Actb } & $5^{\prime}$ & 5'-GTATCCATGAAATAAGTGGTTACAGG-3' & NM_007393 \\
\hline & $3^{\prime}$ & 5'-GCAGTACATAATTTACACAGAAGCAAT-3' & \\
\hline
\end{tabular}

with saline was inserted into the jugular vein, and the outer portion of the tubing was tunneled subcutaneously, exiting at the nape of the neck. The length of tubing inserted into the jugular vein was $5 \mathrm{~mm}$ (71). Once the tubing was in place, it was filled with saline to maintain patency and was closed at the end with a metal stopper.

Infusion study. The mice were randomly assigned to receive intravenous infusions of $6 \mathrm{mM} \mathrm{OA}$ (SigmaAldrich) bound to FA-free albumin (the ratio of OA to BSA was 5:1) or 20\% Intralipid (Abbott Laboratories) or saline. Albumin-bound OA was prepared as previously described (55). Intralipid was composed of (by weight) $20 \%$ soybean oil, $1.2 \%$ phospholipid, $2.25 \%$ glycerol, $76.55 \%$ water. The FA composition of the soybean oil was: C16:0, 10.4\%; C18:0, 4.0\%; C18:1, 23.5\%;

Nuclear fractionation. After treatment with OA, IL, or tunicamycin, cytosolic and nuclear extracts were isolated using the Nuclear Extraction Kit (Panomics) according to the manufacturer's protocol. Briefly, cells on 35-mm plates were washed with cold PBS twice. Buffer A (100 $\mu \mathrm{l} ; 10 \mathrm{mM}$ HEPES, pH 7.9, $10 \mathrm{mM} \mathrm{KCl,} 10 \mathrm{mM}$ EDTA, $1 \mathrm{mM}$ dithiothreitol, 0.4\% [octylphenoxy] polyethoxyethanol, plus protease inhibitors) was added, and the plate was put on a rocking platform at $4{ }^{\circ} \mathrm{C}$ for 10 minutes. Cells were scraped from the plates, and cell clumps were disrupted by repetitive pipetting. The suspension was centrifuged at $20,000 \mathrm{~g}$ at $4^{\circ} \mathrm{C}$ for 3 minutes, and the supernatant was collected (cytoplasmic fraction). The pellet was resuspended into $20 \mu \mathrm{l}$ of buffer B (20 mM HEPES, pH 7.9, $200 \mathrm{mM} \mathrm{NaCl}$, $1 \mathrm{mM}$ EDTA, $10 \%$ glycerol, $1 \mathrm{mM}$ dithiothreitol, plus protease inhibitors) by vigorous vortexing for 5 minutes and then at a medium vortex setting for 30 minutes at $4^{\circ} \mathrm{C}$. The suspension was centrifuged at $20,000 \mathrm{~g}$ at $4^{\circ} \mathrm{C}$ for 5 minutes, and the supernatant was collected (nuclear fraction). Equal amounts of protein extracts were subjected to $8 \%$ SDS-PAGE, transferred to nitrocellulose membranes, and immunoblotted using standard methods as described above. Membranes were stripped and reprobed with antibodies against nucleophosmin to control for nuclear extraction. The primary antibodies used were XBP1 (Santa Cruz Biotechnologies Inc.) and mouse anti-nucleophosmin (Zymed).

Quantitative real-time PCR. Total RNA samples were used for cDNA synthesis with oligo-dT primers using a commercial kit from Invitrogen. The resulting cDNA samples were then quantified for each test gene using target gene-specific primers. Quantitative real-time PCR was done using SYBR Green PCR Master Mix (Applied Biosystems) according to the protocols provided by the manufacturer. Detection of specific products was performed in triplicate using the Mx4000 Multiplex Quantitative PCR system (Stratagene). Using the standard curve method, the relative quantitation of specific PCR products for each primer set was generated. For normalization, GAPDH or $A c t b$ was amplified from each sample. The primers used in the real-time PCR are shown in Table 1.

Animals. The animals studied were male C57BL/6J mice, age 12-14 weeks, purchased from The Jackson Laboratory. All mice were maintained on a 12-hour light/12-hour dark cycle (light cycle was 7 am to $7 \mathrm{pm}$ ) and on a regular rodent chow diet. Animal studies were approved by the Institutional Animal Care and Use Committee of Columbia University College of Physicians and Surgeons.

Surgical procedures. Mice were anesthetized with $3.3 \mu \mathrm{l} / \mathrm{g}$ body weight of ketamine $(15 \mathrm{mg} / \mathrm{ml})$ and xylazine $(3 \mathrm{mg} / \mathrm{ml})$. The incision, location of the jugular vein, insertion of the cannula, and closing of the wound were carried out with a dissection microscope after the operative procedure developed for rats (70). In brief, silicone rubber tubing $(0.51-\mathrm{mm}$ inner diameter $\times$ 0.94-mm outer diameter; catalog 11-189-15A; Fisher) filled
C18:2, 53.5\%; C18:3, 8.3\%. On the morning of the experiment, food was removed, and the silicone tubing was flushed with saline and connected through polyethylene tubing to a KDS 220 Infusion Pump (KD Scientific Inc.). The infusion line ran inside a tether and through a swivel, which was suspended from the top of the cage. This procedure protected the infusion tubing and allowed the mice complete freedom of movement. The infusions were carried out at the rate of $2.5 \mu \mathrm{l} / \mathrm{min}$ for 6 or 9 hours. Blood samples were obtained from the retro-orbital plexus before and at the end of the infusions for measurement of plasma TGs and FAs.

Determination of in vivo $T G$ and $а р о B$ secretion rates. After each 6- or 9-hour infusion, in vivo secretion rates of TGs and apoB were determined as described previously (72). Mice were injected intravenously with 500 $\mathrm{mg} / \mathrm{kg}$ Triton WR1339 (25301-02-4; Sigma-Aldrich) in 0.9\% NaCl. Plasma VLDL clearance is completely inhibited in mice under these conditions (73), and the accumulation of VLDL lipids and apolipoproteins in plasma after injection of Triton can be used to estimate rates of secretion of VLDL into the plasma compartment. Blood samples were collected at the end of infusion ( 0 minutes, preinjection) and at 30,60,90, and 120 minutes after injection of Triton for determination of TG levels, with the rate of rise of TGs in plasma over time indicative of the rate at which TG was secreted from the liver (74). apoB secretion rates were measured by injecting each mouse with $200 \mu \mathrm{Ci}$ of $\left[{ }^{35} \mathrm{~S}\right]$ methionine $(1,175 \mathrm{Ci} / \mathrm{mmol}$; PerkinElmer Life Sciences) together with Triton. Blood samples were taken at 60 and 120 minutes after injection, and the accumulation of $\left[{ }^{35} \mathrm{~S}\right]$ methionine-labeled apoB was used to determine the rates of VLDL apoB secretion. In these experiments, $10 \mu \mathrm{l}$ of whole plasma samples was subjected to $4 \%$ SDS-PAGE, and the gel was dried and exposed to $x$-ray films to visualize labeled apoB. The apoB bands on the film were scanned for densitometry measurements.

Determination of liver TG levels. At the end of either 6- or 9-hour infusions, livers from the mice were collected for the measurement of hepatic TG content. Total liver lipids were extracted by a modification of the method of Folch and Lees (75). Briefly, snap-frozen liver tissues (150 mg) were homogenized and extracted twice with a chloroform:methanol (2:1, vol/vol) solution. The organic layer was dried under nitrogen gas and resolubilized in chloroform. An aliquot was resuspended in an aqueous solution containing $2 \%$ Triton X-100 for the determination of TG mass. $\left[{ }^{14} \mathrm{C}\right]$ Triolein (Amersham Biosciences) was added to each sample before lipid extraction to estimate the percent of recovery, and final TG concentrations were adjusted accordingly. Liver TG levels were expressed as micrograms of TG per milligram of liver protein.

Lipid determinations. Total plasma TG and plasma-free FA concentrations were measured by a colorimetric method using commercial kits (catalogs 997-37492 and 994-75409, respectively) from Wako Chemicals. 
PBA treatment of mice. PBA ( $1 \mathrm{~g} / \mathrm{kg}$ body weight) or water was orally administrated twice a day; at 8 am and then at $8 \mathrm{pm}$. We first treated the mice with PBA for 1 day prior to infusion studies, but there was no effect. We next treated the mice for 7 days, including the day of the 9-hour OA infusion.

Statistics. All data are presented as mean \pm SD. Differences in the mean values between 2 groups were assessed by 2 -tailed Student's $t$ test. Differences in mean values among more than 2 groups were determined by ANOVA. $P<0.05$ was considered to be statistically significant.

\section{Acknowledgments}

This work was supported by the following grants: NIH/National Heart, Lung, and Blood Institute R01 HL55638 and R01 HL73030
(H.N. Ginsberg) and the Japan Heart Foundation/Bayer Yakuhin Research Grant Abroad (T. Ota).

Received for publication May 21, 2007, and accepted in revised form October 3, 2007.

Address correspondence to: Henry N. Ginsberg, Department of Medicine, PH 10-305, 630 West 168th Street, New York, New York 10032, USA. Phone: (212) 305-9562; Fax: (212) 305-3213; E-mail: hng1@columbia.edu.

Tsuguhito Ota and Constance Gayet contributed equally to this work.
1. Harding, H.P., Calfon, M., Urano, F., Novoa, I., and Ron, D. 2002. Transcriptional and translational control in the mammalian unfolded protein response. Annu. Rev. Cell. Dev. Biol. 18:575-599.

2. Kaufman, R.J., et al. 2002. The unfolded protein response in nutrient sensing and differentiation. Nat. Rev. Mol. Cell Biol. 3:411-421.

3. Mori, K. 2000. Tripartite management of unfolded proteins in the endoplasmic reticulum. Cell. 101:451-454.

4. Harding, H.P., Zhang, Y., and Ron, D. 1999. Protein translation and folding are coupled by an endoplasmic-reticulum-resident kinase. Nature. 397:271-274.

5. Harding, H., et al. 2000. Regulated translation initiation controls stress-induced gene expression in mammalian cells. Mol. Cell. 6:1099-1108.

6. Marciniak, S.J., and Ron, D. 2006. Endoplasmic reticulum stress signaling in disease. Physiol. Rev. 86:1133-1149.

7. Neuschwander-Tetri, B.A. 2007. Fatty liver and the metabolic syndrome. Curr. Opin. Gastroenterol. 23:193-198.

8. Marceau, P., et al. 1999. Liver pathology and the metabolic syndrome $\mathrm{X}$ in severe obesity. J. Clin. Endocrinol. Metab. 84:1513-1517.

9. Pagano, G., et al. 2002. Nonalcoholic steatohepatitis, insulin resistance, and metabolic syndrome: further evidence for an etiologic association. Hepatology. 35:367-372.

10. Utzschneider, K.M., and Kahn, S.E. 2006. Review: the role of insulin resistance in nonalcoholic fatty liver disease. J. Clin. Endocrinol. Metab. 91:4753-4761.

11. Ford, E.S., Giles, W.H., and Mokdad, A.H. 2004. Increasing prevalence of the metabolic syndrome among U.S. adults. Diabetes Care. 27:2444-2449.

12. Browning, J.D., et al. 2004. Prevalence of hepatic steatosis in an urban population in the United States: impact of ethnicity. Hepatology. 40:1387-1395.

13. Ozcan, U., et al. 2004. Endoplasmic reticulum stress links obesity, insulin action, and type 2 diabetes. Science. 306:457-461.

14. Nakatani, Y., et al. 2005. Involvement of endoplasmic reticulum stress in insulin resistance and diabetes. J. Biol. Chem. 280:847-851.

15. Wellen, K.E., and Hotamisligil, G.S. 2005. Inflammation, stress, and diabetes. J. Clin. Invest. 115:1111-1119.

16. Nakatani, Y., et al. 2004. Modulation of the JNK pathway in liver affects insulin resistance status. J. Biol. Chem. 279:45803-45809.

17. Malhi, H., Bronk, S.F., Werneburg, N.W., and Gores, G.J. 2006. Free fatty acids induce JNKdependent hepatocyte lipoapoptosis. J. Biol. Chem. 281:12093-12101.

18. Fisher, E.A., and Ginsberg, H.N. 2002. Complexity in the secretory pathway: the assembly and secretion of apolipoprotein B-containing lipoproteins. J. Biol. Chem. 277:17377-17380.

19. Shelness, G.S., Ingram, M.F., Huang, X.F., and
DeLozier, J.A. 1999. Apolipoprotein B in the rough endoplasmic reticulum: translation, translocation and the initiation of lipoprotein assembly. J. Nutr. 129:456S-462S.

20. Yao, Z., Tran, K., and McLeod, R.S. 1997. Intracellular degradation of newly synthesized apolipoprotein B. J. Lipid Res. 38:1937-1953.

21. Gaull, G., Sturman, J.A., and Schaffner, F. 1974. Homocystinuria due to cystathionine synthase deficiency: enzymatic and ultrastructural studies. J. Pediatr. 84:381-390.

22. Gulsen, M., et al. 2005. Elevated plasma homocysteine concentrations as a predictor of steatohepatitis in patients with non-alcoholic fatty liver disease. J. Gastroenterol. Hepatol. 20:1448-1455.

23. Werstuck, G.H., et al. 2001. Homocysteine-induced endoplasmic reticulum stress causes dysregulation of the cholesterol and triglyceride biosynthetic pathways. J. Clin. Invest. 107:1263-1273.

24. Macri, J., and Adeli, K. 1997. Conformational changes in apolipoprotein B modulate intracellular assembly and degradation of apoB-containing lipoprotein particles in HepG2 cells. Arterioscler. Thromb. Vasc. Biol. 17:2982-2994.

25. Ingram, M.F., and Shelness, G.S. 1996. Apolipoprotein B-100 destined for lipoprotein assembly and intracellular degradation undergoes efficient translocation across the endoplasmic reticulum membrane. J. Lipid Res. 37:2202-2214.

26. Qiu, W., et al. 2005. Glucosamine-induced endoplasmic reticulum stress promotes ApoB100 degradation. Arterioscler. Thromb. Vasc. Biol. 25:571-577.

27. Morris, J.A., Dorner, A.J., Edwards, C.A., Hendershot, L.M., and Kaufman, R.J. 1997. Immunoglobulin binding protein $(\mathrm{BiP})$ function is required to protect cells from endoplasmic reticulum stress but is not required for the secretion of selective proteins. J. Biol. Chem. 272:4327-4334.

28. Calfon, M., et al. 2002. IRE1 couples endoplasmic reticulum load to secretory capacity by processing the XBP-1 mRNA. Nature. 415:92-96.

29. Yoshida, H., Matsui, T., Yamamoto, A., Okada, T., and Mori, K. 2001. XBP1 mRNA is induced by ATF6 and spliced by IRE1 in response to ER stress to produce a highly active transcription factor. Cell. 107:881-891.

30. Fisher, E.A., et al. 1997. The degradation of apolipoprotein B100 is mediated by the ubiquitinproteasome pathway and involves heat shock protein 70. J. Biol. Chem. 272:20427-20434.

31. Fisher, E.A., et al. 2001. The triple threat to nascent apolipoprotein B. Evidence for multiple, distinct degradative pathways. J. Biol. Chem. 276:27855-27863.

32. Pan, M., et al. 2004. Lipid peroxidation and oxidant stress regulate hepatic apolipoprotein B degradation and VLDL production. J. Clin. Invest. 113:1277-1287.

33. Vilatoba, M., et al. 2005. Sodium 4-phenylbutyrate protects against ischemia reperfusion injury by inhibition of endoplasmic reticulum-stress mediated apoptosis. Surgery. 138:342-351.

34. Ozcan, U., et al. 2006. Chemical chaperones reduce ER stress and restore glucose homeostasis in a mouse model of type 2 diabetes. Science. 313:1137-1140.

35. Zhang, Y.-L., et al. 2004. Regulation of hepatic apolipoprotein B-lipoprotein assembly and secretion by the availability of fatty acids 1 : differential effects of delivering fatty acids via albumin or remnant-like emulsion particles. J. Biol. Chem. 279:19362-19374.

36. Reaven, G.M. 1988. Role of insulin resistance in human disease. Diabetes. 37:1595-1607.

37. Avramoglu, R.K., Qiu, W., and Adeli, K. 2003. Mechanisms of metabolic dyslipidemia in insulin resistant states: deregulation of hepatic and intestinal lipoprotein secretion. Front. Biosci. 8:d464-d476.

38. Ginsberg, H.N., Zhang, Y.L., and Hernandez-Ono, A. 2005. Regulation of plasma triglycerides in insulin resistance and diabetes. Arch. Med. Res. 36:232-240.

39. Lewis, G.F. 1999. Fatty acid regulation of very low density lipoprotein (VLDL) production. Curr. Opin. Lipidol. 10:475-477.

40. Ozawa, K., et al. 2005. The endoplasmic reticulum chaperone improves insulin resistance in type 2 diabetes. Diabetes. 54:657-663.

41. Lee, J.N., Song, B., DeBose-Boyd, R.A., and Ye, J. 2006. Sterol-regulated degradation of insig-1 mediated by the membrane-bound ubiquitin ligase gp78. J. Biol. Chem. 281:39308-39315.

42. Sparks, J.D., and Sparks, C.E. 1994. Insulin regulation of triacylglycerol-rich lipoprotein synthesis and secretion. Biochim. Biophys. Acta. 1215:9-32.

43. Lewis, G.F., Uffelman, K.D., Szeto, L.W., and Steiner, G. 1993. Effects of acute hyperinsulinemia on VLDL triglyceride and VLDL apoB production in normal weight and obese individuals. Diabetes. 42:833-842.

44. Malmstrom, R., et al. 1997. Metabolic basis of hypotriglyceridemic effects of insulin in normal men. Arterioscler. Thromb. Vasc. Biol. 17:1454-1464.

45. Bourgeois, C.S., Wiggins, D., Hems, R., and Gibbons, G.F. 1995. VLDL output by hepatocytes from obese Zucker rats is resistant to the inhibitory effect of insulin. Am. J. Physiol. 269:E208-E215.

46. Taghibiglou, C., et al. 2000. Mechanisms of hepatic very low density lipoprotein overproduction in insulin resistance. Evidence for enhanced lipoprotein assembly, reduced intracellular apoB degradation, and increased microsomal triglyceride transfer protein in a fructose-fed hamster model. J. Biol. Chem. 275:8416-8425.

47. Malmstrom, R., et al. 1997. Defective regulation of triglyceride metabolism by insulin in the liver in NIDDM. Diabetologia. 40:454-462.

48. Karaskov, E., et al. 2006. Chronic palmitate but not oleate exposure induces endoplasmic reticulum stress, which may contribute to INS-1 pancreatic $\beta$-Cell Apoptosis. Endocrinology. 147:3398-3407. 
49. Cnop, M., et al. 2007. Selective inhibition of EIF $2 \alpha$ dephosphorylation potentiates fatty acid-induced ER stress and causes pancreatic $\beta$-cell dysfunction and apoptosis. J. Biol. Chem. 282:3989-3997.

50. Wang, H., Kouri, G., and Wollheim, C.B. 2005. ER stress and SREBP-1 activation are implicated in $\{$ beta $\}$ cell glucolipotoxicity. J. Cell Sci. 118:3905-3915.

51. Borradaile, N.M., et al. 2006. A critical role for eukaryotic elongation faction 1A-1 in lipotoxic cell death. Mol. Biol. Cell. 17:770-778.

52. Wei, Y., Wang, D., Topczewski, F., and Pagliassotti, M.J. 2006. Saturated fatty acids induce endoplasmic reticulum stress and apoptosis independently of ceramide in liver cells. Am. J. Physiol. Endocrinol. Metab. 291:E275-E281.

53. Wang, D., Wei, Y., and Pagliassotti, M.J. 2006. Saturated fatty acids promote endoplasmic reticulum stress and liver injury in rats with hepatic steatosis. Endocrinology. 147:943-951.

54. Liao, W., Hui, T.Y., Young, S.G., and Davis, R.A. 2003. Blocking microsomal triglyceride protein interferes with apoB secretion without causing retention or stress in the ER. J. Lipid Res. 44:978-985.

55. Dixon, J.L., Furukawa, S., and Ginsberg, H.N. 1991. Oleate stimulates secretion of apolipoprotein B-containing lipoproteins from Hep G2 cells by inhibiting early intracellular degradation of apolipoprotein B. J. Biol. Chem. 266:5080-5086.

56. Sakata, N., Wu, X., Dixon, J.L., and Ginsberg, H.N. 1993. Proteolysis and lipid facilitated translocation are distinct but competitive processes which regulate secretion of apolipoprotein B in HepG2 cells. J. Biol. Chem. 268:22967-22970.

57. Olofsson, S.-O., Stillemark-Billton, P., and Asp, L. 2000. Intracellular assembly of VLDL. Two major steps in separate cell compartments. Trends Cardiovasc. Med. 10:338-345.

58. Liang, J.-S., and Ginsberg, H.N. 2001. Microsomal triglyceride transfer protein binding and lipid transfer activities are independent of each other, but both are required for secretion of apoB lipoproteins from liver cells. J. Biol. Chem. 276:28606-28612.

59. Sparks, J.D., et al. 1997. Effects of fatty acids on apolipoprotein B secretion by McArdle PH-7777 rat hepatoma cells. Biochim. Biophys. Acta. 1347:51-61.

60. Zhou, M., Fisher, E.A., and Ginsberg, H.N. 1998. Regulated co-translational ubiquitination of apoliprotein B100. A new paradigm for proteasomal degradation of a secretory protein. J. Biol. Chem. 273:24649-24653.

61. Pan, M., Liang, J.S., Fisher, E.A., and Ginsberg, H.N. 2000. Inhibition of translocation of nascent apolipoprotein B across the endoplasmic reticulum membrane is associated with selective inhibition of the synthesis of apolipoprotein B. J. Biol. Chem. 275:27399-27405.

62. Qiu, W., Avramoglu, R.K., Rutledge, A.C., Tsai, J., and Adeli, K. 2006. Mechanisms of glucosamineinduced suppression of the hepatic assembly and secretion of apolipoprotein B-100-containing lipoproteins. J. Lipid Res. 47:1749-1761.

63. Oyadomari, S., et al. 2006. Cotranslocational degradation protects the stressed endoplasmic reticulum from protein overload. Cell. 126:727-739.

64. Shenkman, M., Tolchinsky, S., Kondratyev, M., and Lederkremer, G.Z. 2007. Transient arrest in proteasomal degradation during inhibition of translation in the unfolded protein response. Biochem. J. 404:509-516.

65. Cohen, F.E., and Kelly, J.W. 2003. Therapeutic approaches to protein-misfolding diseases. Nature. 426:905-909.

66. Rubenstein, R.C., Egan, M.E., and Zeitlin, P.L. 1997. In vitro pharmacologic restoration of CFTR-mediated chloride transport with sodium 4-phenylbutyrate in cystic fibrosis epithelial cells containing delta F508-CFTR. J. Clin. Invest. 100:2457-2465.

67. Burrows, J.A., Willis, L.K., and Perlmutter, D.H 2000. Chemical chaperones mediate increased secretion of mutant alpha 1-antitrypsin (alpha 1-AT) Z: a potential pharmacological strategy for prevention of liver injury and emphysema in alpha 1-AT deficiency. Proc. Natl. Acad. Sci. U. S. A. 97:1796-1801.

68. McGuinness, M.C., Zhang, H.P., and Smith, K.D 2001. Evaluation of pharmacological induction of fatty acid beta-oxidation in X-linked adrenoleukodystrophy. Mol. Genet. Metab. 74:256-263.

69. Adiels, M., et al. 2006. Overproduction of large VLDL particles is driven by increased liver fat content in man. Diabetologia. 49:755-765.

70. Smith, S.G., and Davis, W.M. 1974. A method for chronic intravenous drug administration in the rat. In Methods in narcotics research. S. Ehrenpreis and A. Neidle, editors. Marcel Dekker. New York, New York, USA. 3-32.

71. Barr, J.E., Holmes, D.B., Ryan, L.J., and Sharpless, S.K. 1979. Techniques for the chronic cannulation of the jugular vein in mice. Pharmacol. Biochem. Behav. 11:115-118.

72. Siri, P., et al. 2001. Post-transcriptional stimulation of the assembly and secretion of triglyceride-rich apolipoprotein B-lipoproteins in a mouse with selective deficiency of brown adipose tissue, obesity and insulin resistance. J. Biol. Chem. 276:46064-46072.

73. Scanu, A.M. 1965. Factors affecting lipoprotein metabolism. Adv. Lipid Res. 3:63-138.

74. Otway, S. 1967. The use of a non-ionic detergent (Triton WR 1339) to determine rates of triglyceride entry into the circulation of the rat under different physiological conditions. J. Physiol. 190:321-332.

75. Folch, J., and Lees, M. 1957. A simple method for the isolation and purification of total lipids from animal tissues. J. Biol. Chem. 224:497-509. 